\title{
Multi-resolution wavelet pitch controller for spar-type floating offshore wind turbines including wave-current interactions
}

\author{
Saptarshi Sarkar ${ }^{\mathrm{a}}$, Lin Chen ${ }^{\mathrm{a}}$, Breiffni Fitzgerald ${ }^{\mathrm{a}, *}$, Biswajit Basu ${ }^{\mathrm{a}}$ \\ ${ }^{a}$ Department of Civil, Structural and Environmental Engineering, Trinity College Dublin, Dublin, Ireland
}

\begin{abstract}
This paper proposes a wavelet multi-resolution based individual pitch control strategy for spar-type floating offshore wind turbines (FOWTs) and investigates its performance under joint wind-wave-current loads considering the effects of wave-current interactions. A multi-resolution analysis (MRA) based wavelet controller that modifies an optimal control problem cast in linear quadratic regulator (LQR) form constrained to a band of frequency has been used in this paper. The weighting matrices of the LQ regulator are varied in different frequency bands depending on the emphasis to be placed on the response energy and control effort to minimize the cost functional of that frequency band. This formulation results in frequency band dependent controller gains that lead to a time-varying controller. Daubechies wavelet is used in the MRA based filter that ensures perfect decomposition of the time signal over a finite interval and fast numerical implementation for control application. The multi-resolution wavelet-LQR individual blade pitch controller is used to control blade out-of-plane vibrations with additional emphasis on $1 \mathrm{P}$ frequency of the wind turbine. The emphasis on 1P frequency along with the blade's out-of-plane natural frequency is shown to reduce aerodynamic loads corresponding to $1^{\text {st }}$ rotational frequency of the wind turbine which in turn reduces vibrations in other modes of the wind turbine. The proposed controller is simulated using a 5-MW baseline offshore wind turbine with realistic operational conditions including wave-current interactions. The controller has been proved to be effective in every analyzed met-ocean condition.
\end{abstract}

Keywords: Multi-resolution wavelet LQR, individual pitch control, wave-current interaction, spar-type floating offshore wind turbine

\section{Introduction}

Most commercial wind turbines use proportional-integral (PI) collective blade-pitch control to regulate rotor speed in the above-rated wind speed regime. A major drawback of this type of controller is that it assumes that all the blades have similar structural properties and are subject to similar aerodynamic 5 loads which is seldom the case. Also, these controllers are designed to regulate the rotor speed and are not designed for structural vibration/load reduction. Most work on vibration control of wind turbines use external damping devices to reduce unwanted vibrations [1-14]. These studies present various passive, semiactive and active structural control using damping devices. But installation of these auxiliary devices has not gained popularity in the wind turbine industry. This opens up the possibility of designing controllers 10 that uses existing actuators and sensors like the blade pitch actuators to reduce structural loads/vibrations while maintaining the required rotor speed. Recently, researchers have proposed a number of pitch control strategies for structural load control in blades/rotor $[15,16]$, tower $[17,18]$ and drive-train $[19,20]$. Structural load mitigation in wind turbines has become an important aspect of its design. The main focus has been

\footnotetext{
* Corresponding author

Email address: fitzgeb7@tcd.ie (Breiffni Fitzgerald)

URL: sarkars@tcd.ie (Saptarshi Sarkar), chenl1@tcd.ie (Lin Chen), basub@tcd.ie (Biswajit Basu)
} 
on the reduction of $1 \mathrm{P}$ (once per revolution) loads using Individual Pitch Controllers (IPCs) [21, 22] that 15 contribute mainly to the fatigue loads of the components. Field validation of individual pitch control strategies has been performed by [23]. Mitigation of higher harmonic loads in the wind turbine has been attempted by [24-26]. Authors in [25] proposed a three-layer control architecture to eliminate long-term wind speed variation like gusts which engulfs the entire rotor, low-frequency aerodynamics loads and highfrequency loads due to wind turbulence. Although the wind turbine rotor is considered symmetric often rotor asymmetries can result in additional structural loads. A control algorithm proposed by [26] has been shown to reduce these loads. Majority of the research focus on load mitigation associated with the blade flapwise bending mode $[15,21,22]$ which experiences the largest aerodynamic loads. An individual pitch control strategy was proposed by [27] with competitive objectives of reducing tower deflection and regulating rotor speed. The control strategies, based on LQR design, were able to reduce tower oscillations at a cost 25 of a slight increase in rotor speed. Reduction in the variation of torque by minimizing edgewise bending moment in the blades was proposed in [28]. The controller not only minimized torque variation but also smoothed flapwise, yaw and tilt bending moments. A multi-variable LQG (Linear Quadratic Gaussian) with feed-forward disturbance controller was proposed by [29] to mitigate rotor tilt and yaw bending moments. The control strategy demonstrated a considerable reduction in yaw and tilt moments when the feed-forward loop was introduced.

A multivariable $\ell_{1}$-optimal pitch control strategy was proposed by [30] to minimize the blade root bending moments while maintaining constant rotor speed in the high wind speed region. Two decoupled LTI (linear time-invariant) models were used to design a CPC (collective pitch control) and an IPC (individual pitch control) to achieve this goal. Instead of using measured data of load for controller design, local inflow

35 measurements (angle of attack, effective wind speeds) on each blade were used to compute blade bending moments for designing an individual pitch controller in [31, 32]. These control strategies were able to reduce structural load without a major loss in long term power production as is seen in state-of-art load reduction concepts. Multi-variable period disturbance accommodating controller (DAC) was proposed by [33, 34] to mitigate persistent wind variations. Periodic DAC was used by [33] to regulate rotor speed while [34] used 40 the same control strategy to regulate rotor speed and mitigate cyclic blade loads in a 2 bladed wind turbine. IPC was shown to be ineffective in improving speed regulation but showed potential in reducing structural loads. In [35] the performance of a full-state feedback controller with periodic gains was compared against a controller with constant gain. It was found that the periodic gain controller had marginal performance improvements compared to the constant gain controller. Wind turbine pitch controller based on stochastic

45 disturbance accommodating controller (SDAC) was presented by [36, 37]. Good performance was reported by [36] with regards to speed regulation and drive-train vibration mitigation. In [37] the controller was used to damp $1 \mathrm{P}$ vibration while maintaining the generator speed near the rated value. The controller showed promising capabilities in reducing blade flapwise displacements while maintaining rotor speed in a satisfactory range. A linear matrix inequality (LMI) based collective pitch controller for speed regulation 50 and an individual pitch controller for $1 \mathrm{P}$ load mitigation was proposed by [38]. The performance showed a reasonable trade-off between speed regulation and load reduction. An LQG controller with Genetic Algorithm for online determination of controller gains was used by [39] to regulate generator speed, active and reactive torque. A fuzzy logic based individual pitch controller was proposed by [40] with similar objectives of regulating rotor speed and minimizing structural loads. A wind-turbine collective-pitch control

55 via a fuzzy predictive algorithm was proposed by [41]. Model predictive controller with pitch actuator constraints was designed to maintain rate rotor speed. In [42], two advanced controllers called fuzzy PID (FPID) and fractional-order fuzzy PID (FOFPID) are proposed to improve the pitch control performance. The unknown parameters of the controllers were estimated using chaotic evolutionary optimization methods with guaranteed optimality based on a chosen objective function. A similar fuzzy logic individual pitch controller to optimise a trade-off among several control objectives such as blade root moment and generator torque was proposed in [43]. A nonlinear state feedback torque controller and linear pitch controller was used in [44] to regulating generator speed and reduce structural loads. A model predictive control strategy based on LIDAR measurements of upstream wind was proposed by [45-47] to regulate rotor speed and reduce asymmetric aerodynamic loads. Promising load reduction on blades and tower was reported. The 65 authors also reported that reduction in pitch activity was achieved when information about the future wind 
disturbance was included in the optimal control theory. A self-optimizing pitch control method based on the active-disturbance-rejection control theory is proposed by [48] to regulate the amplification coefficient automatically and keep the variation of pitch rate and rotor speed in proper ranges. Novel PI and PID based pitch control techniques have been proposed by [49] by synthesizing the optimization for PI parameters 70 tuning, the estimation for unknown delay-perturbations, and the compensation for removing effects from delay-perturbations to actual outputs in wind turbine pitch control systems. A Nonlinear PI(N-PI) pitch controller has been designed by [50] to regulate the wind turbine to capture the rated wind power when the wind speed exceeds the rated value. Unlike the gain-scheduled PI controller, only one set of PI parameters is needed to be tuned to cover the whole operation region. Lin et al. [51] proposes a mixed $\mathrm{H}_{2} / \mathrm{H}_{\infty}$ control 75 strategy with a Markovian jump model to regulate generator speed while reducing fatigue loads on the wind turbine. An adaptive controller is proposed to both regulate generator speed and mitigate component loads under turbulent wind field with blade stiffness uncertainties and compared with the standard gain scheduled proportional integral control and the disturbance accommodating control (DAC) in [52]. An investigation into the three popular IPC techniques; those based on the Clarke and Coleman transforms and 80 single-blade control has been presented by [53]. A fault-tolerant control (FTC) scheme was proposed by [54] that incorporates a traditional PI controller as a baseline system to achieve nominal pitch performance and a fault compensator to eliminate the actuator fault effects. A novel maximum power point tracking (MPPT)-pitch angle control strategy based on Neural Network, to operate the PMSG at an optimal speed to extract maximum power when this available power is lower than nominal power and limit the extra power has been proposed by [55].

Individual blade pitch control strategies for floating offshore wind turbines have been investigated by [56-59]. Namik and Stol [56] used a periodic state space controller that utilizes individual blade pitching to improve power output and reduce platform motions in above-rated wind speed region. Individual blade pitch state space (IBP SS) control and DAC are applied on a $5 \mathrm{MW}$ wind turbine mounted on the barge 90 and tension leg floating platforms for performance comparison in above-rated wind speed region to regulate rotor speed and reduce loads on the tower in [57]. A multi-objective state feedback controller is proposed to reduce tower fore-aft and side-to-side bending fatigue loads in a spar-type offshore wind turbine in [58]. Li et al. [59] investigates the suppression of undesired turbine's motion by a rotor thrust control by two kinds of pitch control systems: steady pitch control and cyclic pitch control and characterize the FOWT aerodynamic performance under different pitch angles using wind tunnel experiments.

The above literature review presents various works from over a decade on IPC for load reduction and improving power production. The control strategies vary from simple SISO PI controllers to sophisticated MIMO controllers using fuzzy logic or model predictive controllers. While these control strategies focus on improvement of power production and/or structural load reduction there is always a trade-off between the two conflicting requirements. The use of wavelet-LQR control strategy that is suitable for a time-varying system as described in [60, 61] has not been employed for offshore wind turbines. Recently, Fitzgerald et al. [62] used the wavelet-LQR control strategy to minimize blade out-of-plane displacement. However, developing a control strategy for offshore wind turbines presents additional challenges since the stability of the entire system (especially the platform roll and pitch degrees of freedom) must be considered. Further, the wave-current interaction has recently been incorporated in the analysis of FOWTs [63, 64]. Considerable effects on the structural responses and fatigue loads have been observed thereof. However, the interaction effects have not been included in previous studies on vibration control of wind turbines. Besides, a simplified model for the FOWT blades and tower was used in $[63,64]$ while the present study uses a more comprehensive model with the same number of degrees-of-freedom as FAST [65]. Based on the literature review presented above this paper proposes to

- Design a wavelet-LQR based individual pitch controller for the floating offshore wind turbine with the primary target of minimizing blade out-of-plane vibrations. Compare its performance against the standard baseline controller and a classical LQR based individual blade pitch controller.

- Model the effect of wave-current interaction considering different current profiles to estimate joint wave-current loads on the spar of the floating wind turbine. Further, investigate whether an underlying current has an effect on controller performance. 
- Examine controller performance in the range of region 3 of operation wind speeds.

\section{Offshore floating wind turbine model}

A multi-body dynamic model of the offshore wind turbine is developed using Kane's method [66]. Kane's method, which emerged recently, reduces the labour needed to derive equations of motion and leads to equations that are simpler and more readily solved by a computer, in comparison to earlier, classical approaches. State of the art wind turbine simulation tools like FAST [65] also employ Kane's method to model offshore wind turbines. This method presents a powerful vector approach that offers considerable advantages over the tradition Euler-Lagrangian formulation as, the dynamical equations of motion of complicated systems can be obtained from its kinematics, in a form that can be directly solved using a computer.

For proper modelling of the offshore wind turbine, it is necessary that every component is defined in its local coordinate system and then referred back to the global, in this case, inertial reference frame. Hence, local coordinate systems are assigned to the platform, tower nodes, tower-top, nacelle, low-speed shaft and the blades. The blades have more than one coordinate system assigned to them. For detailed modelling of the blades, they are referred to their coned coordinate system followed by the pitched coordinate system. Aerodynamic loads are applied on the blade nodes that are not only coned and pitched but also rotated due to elastic deformation of the blades in out-of-plane and in-plane directions. The coordinate systems used (expect the tower and blade element fixed coordinate systems) are shown in Figure 1. The platform rotation and rotation of the elastic members (tower and blades) occurs simultaneously about more than one axis. This restricts the use of a simple Euler rotation matrix to establish transformation relations between subsequent coordinate systems. Although advanced methods can be used to derive these transformation relations, the small magnitude of these angles allows the use of small angle approximation that makes a Euler 1-2-3 rotation matrix independent of the sequence of rotation. The resulting transformation matrix is not orthogonal, hence, singular value decomposition is used to obtain the nearest orthogonal transformation relation. The reader may refer [67] for the transformation relation.

By a direct result of Newton's law of motion, Kane's equations of motion for a simple holonomic multibody system can be stated as[66]

$$
F_{k}+F_{k}^{*}=0 \quad \text { for } k=1,2, \ldots N
$$

where, $N$ is the total number of degrees of freedom required to describe the complete kinematics of the wind turbine system. With a set of $M$ rigid bodies characterized by reference frame $N_{i}$ and center of mass point $X_{i}$. The generalized active force for $k^{\text {th }}$ degree of freedom is given as[66]

$$
F_{k}=\sum_{i=1}^{M}\left[{ }^{E} \mathbf{v}_{k}^{X_{i}} \cdot \mathbf{F}^{X_{i}}+{ }^{E} \omega_{k}^{N_{i}} \cdot \mathbf{M}^{N_{i}}\right]
$$

Where, $\mathbf{F}^{X_{i}}$ is force vector acting on the center of mass of point $X_{i}$ and $\mathbf{M}^{N_{i}}$ is the moment vector acting on the $N_{i}$ rigid body. ${ }^{E} \mathbf{v}_{k}^{X_{i}}$ and ${ }^{E} \omega_{k}^{N_{i}}$ are the partial linear and partial angular velocity of the point $X_{i}$ and rigid body $N_{i}$ respectively associated with the $k^{t h}$ degree of freedom in the inertial $(E)$ reference frame. The generalized inertia force for $k^{\text {th }}$ degree of freedom is given as

$$
F_{k}^{*}=-\sum_{i=1}^{M}\left[{ }^{E} \mathbf{v}_{k}^{X_{i}} \cdot\left(m^{N_{i} E} \mathbf{a}^{X_{i}}\right)+{ }^{E} \omega_{k}^{N_{i}} \cdot{ }^{E} \dot{\mathbf{H}}^{N_{i}}\right]
$$

where it is assumed that for each rigid body $N_{i}$, the inertia forces are applied at the centre of the mass point $X_{i} .{ }^{E} \dot{\mathbf{H}}^{N_{i}}$ is the time derivative of the angular momentum of rigid body $N_{i}$ about its center of mass $X_{i}$ in the inertial frame[66]. For the wind turbine model, the mass of the platform, tower, yaw bearing, nacelle, hub, blades, generator contributes to the total generalized inertia forces. Generalized active forces are the forces applied directly to the wind turbine system, forces that ensure constraint relationships between the various rigid bodies and internal forces within flexible members. Forces applied directly on the offshore 
wind turbine system include aerodynamic forces on the blades and the tower, hydrodynamic forces on the platform, mooring forces on the platform, gravitational forces, generator torque, high-speed shaft brake. Here it must be noted that gearbox friction forces are neglected. Yaw springs and damper contribute to forces that enforce constraint relationship between rigid bodies. Internal forces within flexible members include elasticity and damping in tower, blades and drive-train.

As can be observed from the above equations, the kinematic description, i.e., the position, velocity and acceleration vectors of all important points on the offshore wind turbine system is the key requirement. Although the process of obtaining these vectors is tedious, the method is fairly straightforward. To describe the motion of the offshore wind turbine the degrees of freedom/generalized coordinates used are given in equation 4 .

$$
\begin{aligned}
& \mathbf{q}=\left\{\begin{array}{lllllllllllll}
q_{S g} & q_{S w} & q_{H v} & q_{R} & q_{P} & q_{Y} & q_{T F A 1} & q_{T S S 1} & q_{T F A 2} & q_{T S S 2} & q_{y a w} & q_{G e A z} & q_{D r T r}
\end{array}\right.
\end{aligned}
$$

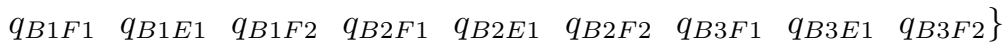

The subscripts define the degrees of freedom under consideration and are described in Appendix A. Once the

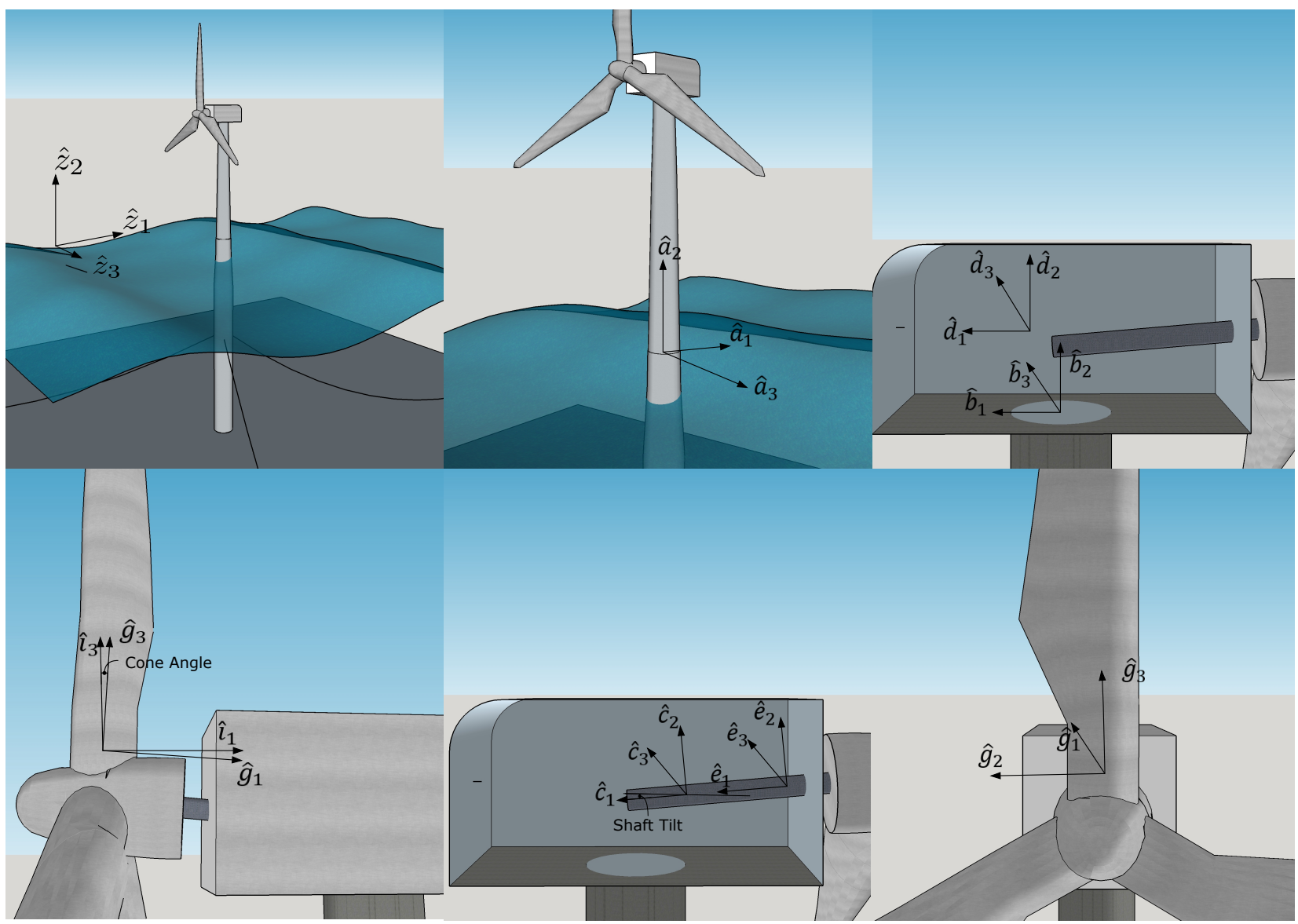

Figure 1: Coordinate systems

linear and angular velocity vectors for every important point and rigid body in the system are defined, the partial linear and angular velocities are obtained as per [66] assuming the time derivatives of the generalized coordinates as the generalized speed (i.e., $u_{k}=\dot{q}_{k}$ ). The complete non-linear time-domain equations of motion for the offshore wind turbine system in its general form can be written as

$$
\mathbf{M}(\mathbf{q}, \mathbf{u}, t) \ddot{\mathbf{q}}=-\mathbf{f}(\dot{\mathbf{q}}, \mathbf{q}, \mathbf{u}, t)
$$


where, $\mathbf{M}$ is the inertial mass matrix that is a non-linear function of the set of degrees of freedom $\mathbf{q}$, control input $\mathbf{u}$, and time $t$. The forcing function $\mathbf{f}$ depends non-linearly on the degrees of freedom, the time derivative of the degrees of freedom, control input and time.

\subsection{Dynamic loads}

Aerodynamic loads. Aerodynamic loads on the wind turbine are estimated using steady Blade Element Momentum (BEM) theory. 3D wind fields are generated using the TurbSim [68] package distributed by National Renewable Energy Laboratory (NREL), USA. The wind fields generated by the TurbSim account for vertical and horizontal wind shear and spatial coherence of the turbulent wind field. The package can be used to generate complete wind field with varying turbulence intensity levels, power-law coefficients for wind shear and the characteristic wind speeds. The steady BEM theory used in this package interpolates the wind speed at the blade nodes from the TurbSim generated 3D wind field to estimate aerodynamic loads based on the quasi-static aerodynamic properties (i.e., lift and drag) of the blades. This theory is widely available in the literature [69-71] and hence, it is not described in this paper. The BEM equations are solved using an approach proposed by Ning [72]. The major change introduced by this approach is to solve for the unknown inflow angle instead of solving for the axial and the tangential induction factors. For this purpose, different equations are used in different solution regions (e.g. momentum, empirical or propeller brake region). Furthermore, the empirical region is estimated using Glauert's correction with Buhl's modification. Adjusting different equations for each region circumvents the traditional two-point factors are also included to account for the vortices generated by the blade tips and the hub. The model is also capable of accounting for skewed inflow using a correction on the axial induction factor proposed by Pitt and Peters as obtained from [73]. The solution of the BEM equations at each section gives the elemental lift and drag forces. The elemental out-of-plane force (thrust) and in-plane force (torque) on the blade sections $[73]$

Hydrodynamic loads. Morison's representation is used to estimate hydrodynamic loads on the cylindrical spar of the floating wind turbine. In conjunction with strip theory, Morison's equations can be used to compute linear wave inertia forces and non-linear viscous drag forces. The total load on the platform is then obtained by integrating the elemental forces along the depth of the platform. The forces associated with a strip $\mathrm{d} z$ of the platform in surge and sway direction are given as

$$
\begin{aligned}
\mathrm{d} F_{i}^{P}(z, t)= & \underbrace{-C_{A} \rho\left(\frac{\pi D(z)^{2}}{4}\right) \ddot{q}_{i}(z, t) \mathrm{d} z}_{\text {added mass }}+\underbrace{C_{M} \rho\left(\frac{\pi D(z)^{2}}{4}\right) a_{i}^{f}(z, t) \mathrm{d} z}_{\text {fluid inertial force }} \\
& +\underbrace{\frac{1}{2} C_{D} \rho D(z)\left(v_{i}^{f}(z, t)-v_{i}^{p}(z, t)\right)\left|v_{i}^{f}(z, t)-v_{i}^{p}(z, t)\right| \mathrm{d} z}_{\text {viscous drag force }} \quad \text { for } i=S g, S w
\end{aligned}
$$

Where, the superscript ' $P$ ' denotes the platform and $\mathrm{d} F_{i}^{P}$ is the elemental force on the platform for the $i^{\text {th }}$ degree of freedom. Similarly, the roll and pitch moments on the platform can be given as

$$
\mathrm{d} M_{i}^{P}(z, t)= \begin{cases}-\mathrm{d} F_{S g}^{P}(z, t) z & i=P \\ \mathrm{~d} F_{S w}^{P}(z, t) z & i=R\end{cases}
$$

Where, $\mathrm{d} M_{i}^{P}$ is the elemental moment on the platform for the $i^{\text {th }}$ degree of freedom. The total forces and moments on the platform are obtained by integration of the elemental forces and moments along the depth of the platform Since, the spar is symmetrical about its vertical axis, the yaw moment and heave force are assumed to be zero. Orison's representation assumes that viscous drag force dominates the total drag force and radiation damping is negligible. This is valid only for rigid platforms with small motion, which is true in this case. Equation 6 does not include the added mass associated with the heave motion of the platform. Hence, added mass coefficient for heave degree of freedom is included as per [74]. 


\subsection{Mooring dynamics model}

An open-source mooring system simulation program, named OpenMOOR [75], is used to compute the mooring force for given reference point motion of the platform. The program is based on the model of submerged cables, as in Figure 2, developed by [76-78], where the cable is modelled as an Euler beam considering the bending and torsional stiffness effects. The hydrodynamic effect is considered using the modified Morison's equation. In the case that a part of the cable is grounded on the seabed, the seabed is considered as a flat plane modelled as a visco-elastic mattress. The stiffness of the seabed was taken from the FAST [65] case files for the mooring system of the spar-type FOWT. According to the literature, the cable fairlead forces and hence the FOWT motion are not sensitive to the value of the stiffness. We have also performed a parametric analysis and confirmed that. The seabed stiffness is important if the focus is the fatigue analysis of the cable near the touchdown point. Using OpenMOOR, the fairlead motion is computed using the multi-body dynamics and then the two-point boundary problem for each cable is solved in parallel using the generalized- $\alpha$ method for both spatial and temporal discretization [78]. The resulting nonlinear algebraic equation is eventually solved using a Newton-like method with dynamic relaxation. OpenMOOR also enables the consideration of steady current with an arbitrary profile. In the present study, the wave effect on the mooring cable is neglected since the fairleads of the spar-type FOWT are deep below the mean water level. For implementation, OpenMOOR is compiled as a dynamic linking library and then coupled with the model of the FOWT. The coupling is achieved by returning the displacements and velocities of

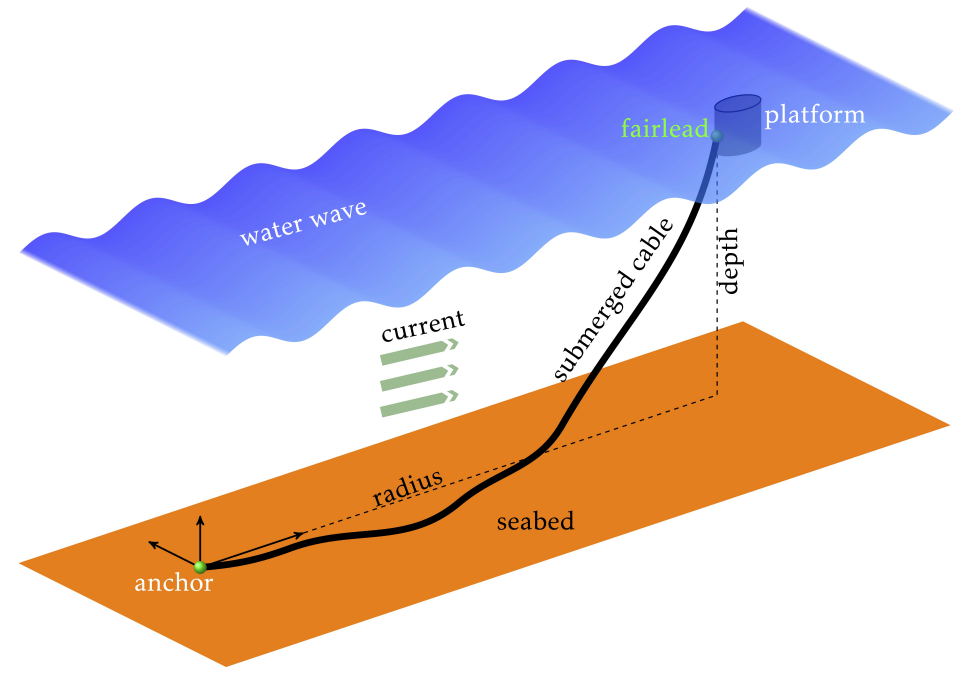

Figure 2: Submerged cable subjected to wave and current

the platform reference point to OpenMoor and applying the obtained mooring loads to the platform. This creates one time step lag between the platform state and mooring loads. But, with sufficiently small time step this requirement can be waived and is the standard practise in state-of-the-art simulation tools like FAST [65].

\subsection{Wave-current interaction model}

The wave-current interaction is modelled using the Airy wave theory considering the effect of an underlying current $[79,80]$. Two-dimensional flow is considered, i.e., the waves are travelling on a favourable and adverse current. For description of the flow field, a coordinate system is defined with the origin placed on the mean water level (MWL) with $x$ the horizontal axis and $z$ the vertical axis pointing upwards.

\subsubsection{Regular wave on current}

Assuming small-amplitude waves travelling on a current, the flow velocity field is expressed as the summation of the flow due to surface wave and the current [81,82], as 


$$
\begin{aligned}
u_{T}(x, z, t) & =U(z)+u(z) \cos (\kappa x-\omega t) \\
w_{T}(x, z, t) & =w(z) \sin (\kappa x-\omega t)
\end{aligned}
$$

where $U(z)$ is the current velocity varying with respect to $z$; and $\omega$ and $\kappa$ denote the angular frequency and the wavenumber respectively. Note that $\omega$ is the apparent frequency with the current effect considered [83]. In the preceding expressions, $u_{T}(x, z, t)$ and $w_{T}(x, z, t)$ are the flow velocities in horizontal and vertical directions, while $u(x, z, t)$ and $w(x, z, t)$ are the wave velocities using the first-order term [81].

According to the Airy wave theory, the free surface elevation $\eta$ is given as

$$
\eta(x, t)=A \cos (\kappa x-\omega t)
$$

where $A=$ the surface wave amplitude. Given the free surface function, the flow velocity can be solved analytically for a uniform or linear current profile $\left(\mathrm{d}^{2} U(z) / \mathrm{d} z^{2}=0\right)$ (see [82] for details), as

$$
\begin{aligned}
& u_{T}(x, z, t)=U(z)+A\left(\omega-\kappa U_{0}\right) \frac{\cosh \left[\kappa\left(z+h_{w}\right)\right]}{\sinh \left(\kappa h_{w}\right)} \cos (\kappa x-\omega t) \\
& w_{T}(x, z, t)=A\left(\omega-\kappa U_{0}\right) \frac{\sinh \left[\kappa\left(z+h_{w}\right)\right]}{\sinh \left(\kappa h_{w}\right)} \sin (\kappa x-\omega t)
\end{aligned}
$$

where $U_{0}=$ the current velocity at $z=0$. The corresponding dispersion relation becomes

$$
\left(\omega-\kappa U_{0}\right)^{2}=\left[\mathrm{g} \kappa-\left(\omega-\kappa U_{0}\right) \frac{\mathrm{d} U}{\mathrm{~d} z}\right] \tanh \left(\kappa h_{w}\right)
$$

which is valid for both uniform and linear shear currents. The solution of the preceding equation gives the wave numbers and the flow field is then explicitly determined using equations $(11,12)$.

\subsubsection{Irregular waves on current}

To consider the current effect on irregular waves, the expressions in equations $(11,12)$ are combined with the spectral representation. The influence of the current on the wave spectrum is considered by [79]

$$
S(\omega, U)=\frac{4 S(\omega)}{(1+\sqrt{1+4 \omega U / \mathrm{g}})^{2} \sqrt{1+4 \omega U / \mathrm{g}}}
$$

where $S(\omega, U)$ and $S(\omega)$ denote the wave spectra with and without an underlying current respectively. It is noted that when $\omega \rightarrow-\mathrm{g} / 4 U$, the wave components are unable to propagate against the current and wave breaking occurs and hence the preceding expression is only valid for $1+4 \omega U / g>0$ if waves are travelling on an adverse current. To deal with the case when wave breaking happens, an "equilibrium limit" was defined for deep water by $[84,85]$ as

$$
S_{\mathrm{ER}}(\omega, U)=\frac{A^{*} \mathrm{~g}^{2}}{(\omega-k U)^{5}} \frac{1}{1+2 U(\omega-\kappa U) / \mathrm{g}}
$$

where the subscript ER refers to the equilibrium range and $A^{*}$ is a numerical constant in the range of $0.008-0.015$ [86]. Equation 15 is used instead for a given wave frequency whenever $S(\omega, U)$ is larger than $S_{\mathrm{ER}}(\omega, U)$.

For irregular waves, the water surface elevation can be expressed as

$$
\eta(x, t)=\sum_{j=1}^{N} A_{j} \cos \left(k_{j} x-\omega_{j} t+\phi_{j}\right)
$$


where $\phi_{j}$ is introduced as a random phase angle uniformly distributed from 0 to $2 \pi$ and $N$ denotes the number of wave components. The amplitude of the $j$ th wave is $A_{j}=\sqrt{2 S\left(\omega_{j}, U\right) \Delta \omega}$ with $\Delta \omega$ the frequency interval. Correspondingly, the flow velocities are given by

$$
\begin{aligned}
& u_{T}(x, z, t)=U(z)+\sum_{j=1}^{N} A_{j}\left(\omega_{j}-\kappa_{j} U\right) \frac{\cosh \left[\kappa_{j}\left(z+h_{w}\right)\right]}{\sinh \left(\kappa_{j} h_{w}\right)} \cos \left(\kappa_{j} x-\omega_{j} t+\phi_{j}\right) \\
& w_{T}(x, z, t)=\sum_{j=1}^{N} A_{j}\left(\omega_{j}-\kappa_{j} U\right) \frac{\sinh \left[\kappa_{j}\left(z+h_{w}\right)\right]}{\sinh \left(\kappa_{j} h_{w}\right)} \sin \left(\kappa_{j} x-\omega_{j} t+\phi_{j}\right)
\end{aligned}
$$

The accelerations can be obtained from the preceding equations, as

$$
\begin{aligned}
\dot{u}_{T}(x, z, t) & =\sum_{j=1}^{N} A_{j} \omega_{j}\left(\omega_{j}-\kappa_{j} U\right) \frac{\cosh \left[\kappa_{j}\left(z+h_{w}\right)\right]}{\sinh \left(\kappa_{j} h_{w}\right)} \sin \left(\kappa_{j} x-\omega_{j} t+\phi_{j}\right) \\
\dot{w}_{T}(x, z, t) & =-\sum_{j=1}^{N} A_{j} \omega_{j}\left(\omega_{j}-\kappa_{j} U\right) \frac{\sinh \left[\kappa_{j}\left(z+h_{w}\right)\right]}{\sinh \left(k_{j} h_{w}\right)} \cos \left(\kappa_{j} x-\omega_{j} t+\phi_{j}\right)
\end{aligned}
$$

where the wave-number $\kappa_{j}$ is solved from equation (13) for each wave component. An instance of the Pierson-Moskowitz spectrum with and without an underlying current is shown in Figure 3. The parameters used are - significant wave height $10 \mathrm{~m}$, peak spectral period $6 \mathrm{~s}$ and surface current velocity $0.609 \mathrm{~m} / \mathrm{s}$ [87]. A decrease in the wave spectrum peak can be observed in the presence of an underlying current.

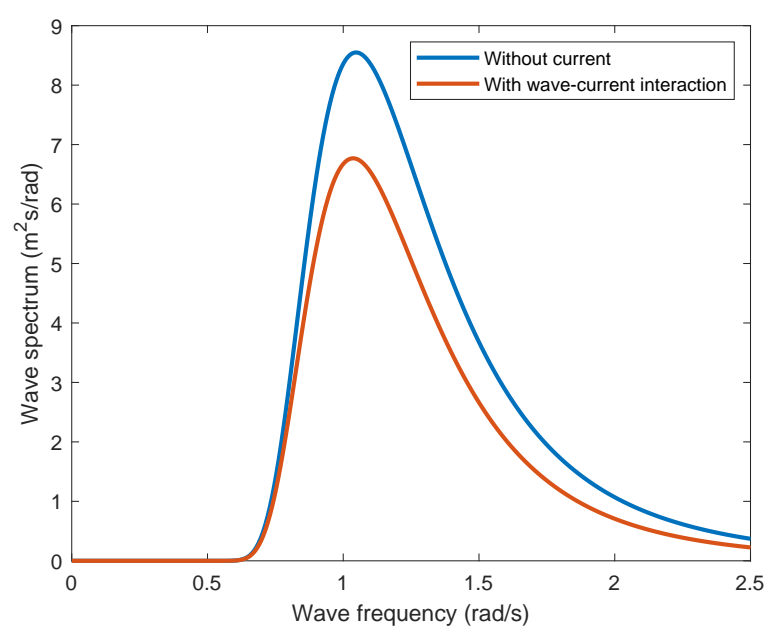

Figure 3: Pierson-Moskowitz spectrum with and without an underlying current

\section{Multi-resolution wavelet-LQR pitch controller}

The controller designed in this section is inspired by the works of $[60,61]$. Its application as an individual pitch controller is described in this section. The wavelet-LQR pitch controller is developed using a reduced order system with primary focus on reduction of blade out-of-plane displacement. With this in view, a 
reduced order system with four degrees of freedom (i.e., the three blade flapwise and tower fore-aft) are used. According to [61], a time-varying system can be represented as

$$
\dot{\mathbf{x}}(t)=\mathbf{A}(t) \mathbf{x}(t)+\mathbf{B}(t) \mathbf{u}(t)+\mathbf{F}(t)
$$

with states $\mathbf{x} \in \Re^{n}$, control input $\mathbf{u} \in \Re^{m}$ and external disturbance $\mathbf{F} \in \Re^{n}$. The reduced order time-varying FOWT can be represented in this form, however, for controller design the closed form state-space equations are not required as will be shown subsequently. The state vector and control input vector are given as

$$
\begin{aligned}
& \mathbf{x}=[\mathbf{q}, \dot{\mathbf{q}}]^{T}, \quad \mathbf{q}=\left[q_{T F A 1}, q_{B 1 F 1}, q_{B 2 F 1}, q_{B 3 F 1}\right] \\
& \mathbf{u}=\left[\beta_{1}, \beta_{2}, \beta_{3}\right]^{T}
\end{aligned}
$$

Wavelet transformation of equation 21 with respect to a basis function $\psi$ with scale parameter $a$ and translation parameter $b$ leads to

$$
W_{\psi_{a}}^{\prime} x_{i}(b)=\sum_{k=1}^{n} W_{\psi_{a}}\left(A_{i k} x_{k}\right)(b)+\sum_{k=1}^{m} W_{\psi_{a}}\left(B_{i k} u_{k}\right)(b)+W_{\psi_{a}} F_{i}(b)
$$

where prime denotes differentiation with respect to the translation parameter $b$ and $W_{\psi_{a}}(\cdot)$ is the wavelet transformation of $(\cdot)$. Since, $\psi[(t-b) / a]$ is a fast decaying function localized around $t=b$ and $A_{i k}(t) \&$ $B_{i k}(t)$ are slowing varying functions as compared to $\psi[(t-b) / a]$ and $x_{k}(t)$; the wavelet transformation of the first two terms in the right hand side of equation 23 can be approximated as

$$
\begin{aligned}
& W_{\psi_{a}}\left(A_{i k} x_{k}\right) \approx A_{0, i k} W_{\psi_{a}} x_{k}(b) \\
& W_{\psi_{a}}\left(B_{i k} x_{k}\right) \approx B_{0, i k} W_{\psi_{a}} x_{k}(b)
\end{aligned}
$$

where, $\mathbf{A}_{0}$ and $\mathbf{B}_{0}$ are the mean (nominal matrices) excluding the time varying components. Therefore, equation 23 can be rewritten as

$$
W_{\psi_{a}}^{\prime} \mathbf{x}(b)=\mathbf{A}_{0} W_{\psi_{a}} \mathbf{x}(b)+\mathbf{B}_{0} W_{\psi_{a}} \mathbf{u}(b)+W_{\psi_{a}} \mathbf{F}
$$

For the non-linear floating wind turbine system the linearised state matrix $\mathbf{A}_{0}$ and linearised control influence matrix $\mathbf{B}_{0}$ can be obtained from a Taylor series expansion till first order terms. The partial differentiations can be performed using numerical central difference technique. For details on the form of the equations refer to [65]. For the system defined in equation 25 in wavelet domain the control input can be written in a state feedback form as

$$
\left\{W_{\psi_{a}} \mathbf{u}\right\}=-\mathbf{G}_{\mathbf{a}}\left\{W_{\psi_{a}} \mathbf{x}\right\}
$$

where, $\mathbf{G}_{a}$ is scale parameter dependent gain matrix, i.e., a frequency band dependent gain matrix. With the control input of the above form a minimization cost functional can be defined as

$$
J_{a}=\int_{t_{0}}^{t_{c}}\left\{W_{\psi_{a}} \mathbf{x}\right\}^{T} \mathbf{Q}_{a}\left\{W_{\psi_{a}} \mathbf{x}\right\}+\left\{W_{\psi_{a}} \mathbf{u}\right\}^{T} \mathbf{R}_{a}\left\{W_{\psi_{a}} \mathbf{u}\right\}
$$

The definition of the cost function leads to the classical LQR problem for wavelet transformed states and control input. The weighting matrices $\mathbf{Q}_{a}, \mathbf{R}_{a}$ are associated to the scaling parameter $a$ and are specified for every frequency band.

Control input in time domain. The control input can be obtained in time domain by inverse wavelet transformation of the control input. The control input at $t=t_{c}$ using the states from the interval $\left[t_{0}, t_{c}\right]$ can be obtained as

$$
\begin{aligned}
\mathbf{u}\left(t_{c}\right)= & -\mathbf{G}_{L} W_{\psi_{a}}^{-1} \int_{0}^{a_{L}} \int_{t_{0}}^{t_{c}} \frac{1}{a^{2}}\left\{W_{\psi_{a}} \mathbf{x}(t)\right\} \psi\left(\frac{t_{c}-b}{a}\right) \mathrm{d} b \mathrm{~d} a \\
& -\sum_{j=L+1}^{U} \mathbf{G}_{j} W_{\psi_{a}}^{-1} \int_{j}^{j+1} \int_{t_{0}}^{t_{c}} \frac{1}{a^{2}}\left\{W_{\psi_{a}} \mathbf{x}(t)\right\} \psi\left(\frac{t_{c}-b}{a}\right) \mathrm{d} b \mathrm{~d} a
\end{aligned}
$$


where, the scaling parameter is discretized into bands $\left\{0, a_{1}, a_{2}, \ldots, a_{L}, \ldots, a_{U}, \ldots\right\}$. Where, $a_{L}$ is the lower threshold of frequency bands, $a_{U}$ is the upper is the upper threshold of frequency bands; and for higher bands $a_{j}>a_{U}$ the control input is ignored.

Since continuous wavelet transform (CWT) is not suitable for synthesis of control input from time histories of finite interval, discrete wavelet transform (DWT) based on MRA is used for exact decomposition/reconstruction of the signal. The filtered signal obtained from MRA is then used to obtain the control input in time domain as

$$
\mathbf{u}=-\mathbf{G}_{L}\{\mathbf{x}\}_{L}-\sum_{j=L+1}^{U} \mathbf{G}_{j}\{\mathbf{x}\}_{j}
$$

from frequency dependent control gains where, $\{\mathbf{x}\}_{L},\{\mathbf{x}\}_{L+1}, \ldots,\{\mathbf{x}\}_{U}$ are the filtered signal corresponding to discretized frequency bands. The frequency band dependent controller gains are estimated using different weighting matrices $\mathbf{Q}_{j}$ and $\mathbf{R}_{j}$ from the solution of the Algebraic Riccati Equation (ARE) associated with the nominal state and control influence matrices $\mathbf{A}_{0}$ and $\mathbf{B}_{0}$. The wavelet-LQR controller is compared against the classical LQR controller where the control input is estimated from gain scheduling of the unfiltered state and frequency band independent controller gain.

For every wind turbine the blade pitch angles, used as the control input, is limited by the pitching rate and maximum pitch angle that can be realized by the pitch actuators of the blades. Hence, the commanded pitch angles obtained from equation 29 are limited by maximum pitching rate of 8 degrees/sec and maximum pitch angle of 90 degrees for the reference wind turbine [88].

\section{Model verification results}

The offshore wind turbine model developed is benchmarked against state of the art wind turbine simulator FAST [65]. The spar-type offshore wind turbine defined in [88] is used for analysis. The codes for the offshore wind turbine are developed in MATLAB [89]. The verification results are shown in Figure 4 and Figure 5. The offshore wind turbine is simulated under steady rated wind speed of $11.4 \mathrm{~m} / \mathrm{s}$ in still water.

An excellent similarity is observed for the wind turbine tower, nacelle and blade motion in Figure 4; while some dissimilarities are observed in the platform motion from Figure 5. The main difference is a phase shift in the response time histories. This is due to the fact that while FAST applies hydrodynamic damping from both linear potential flow theory and viscous drag forces from Morison's equation, the derived model in this paper uses only viscous drag forces from Morison's equation. This difference in hydrodynamic damping results in a phase shift in the response time histories. Also, the degrees of freedom that experience less hydrodynamic damping like platform surge, heave or reaches steady state quickly like platform pitch, yaw is less affected by the phase shift. The platform sway and roll degrees of freedom experience a noticeable phase shift due to the difference in hydrodynamic damping. However, the mean and the frequency content of the responses remain the same which is important from a dynamic analysis point of view.

\section{Controller performance evaluation}

The non-linear aeroelastic offshore wind turbine model is used to simulate the dynamic behaviour of the spar-type floating offshore wind turbine. The different cases are simulated for a standard $600 \mathrm{sec}$ and with a sampling rate of $40 \mathrm{~Hz}$. Numerical Runga-Kutta method 'ODE 4' is used for time integration of the non-linear system. The proposed controller is compared with a baseline PI collective pitch controller and a classical LQR pitch controller to illustrate the effectiveness of the proposed control strategy. The turbulent wind field is generated using the TurbSim[68] package distributed by NREL. It has the capability of generating turbulent 3-D wind field taking into account wind shear and spatial coherence. The turbulence in the wind has been assumed to be $10 \%$ in this paper. Two different wind cases are investigated here, i.e., $14 \mathrm{~m} / \mathrm{s}$ and $25 \mathrm{~m} / \mathrm{s}$ reference wind speed at hub height. The two different wind speeds represent the bound of wind speeds where the pitch control is active (above rated wind speed). The stochastic sea is modelled using the Pierson-Moskowitz spectrum [90]. Significant wave height is assumed to be $10 \mathrm{~m}$ and peak spectral 


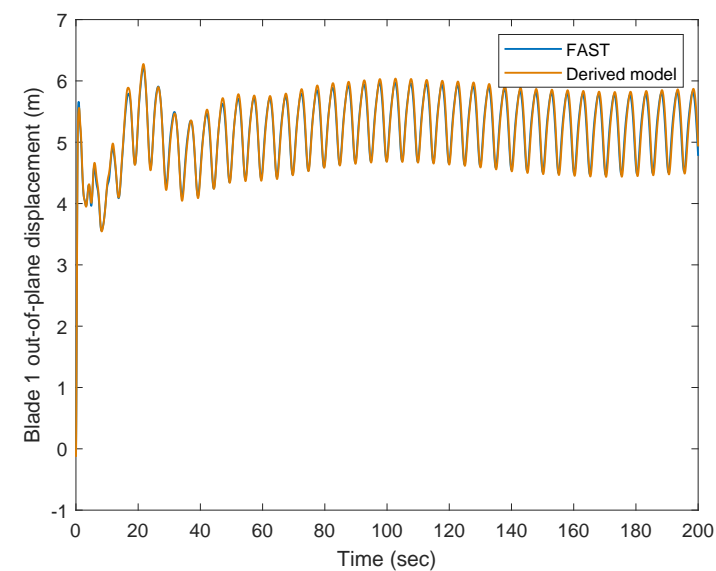

(a) Blade 1 out-of-plane displacement

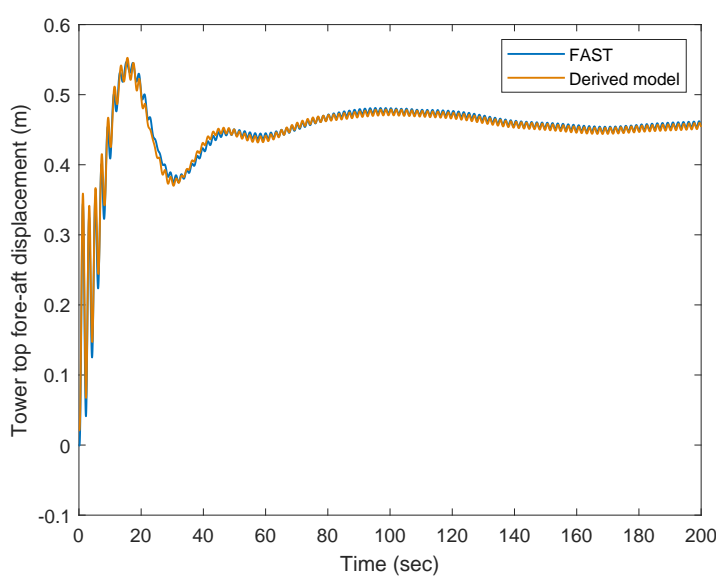

(c) Tower top fore-aft displacement

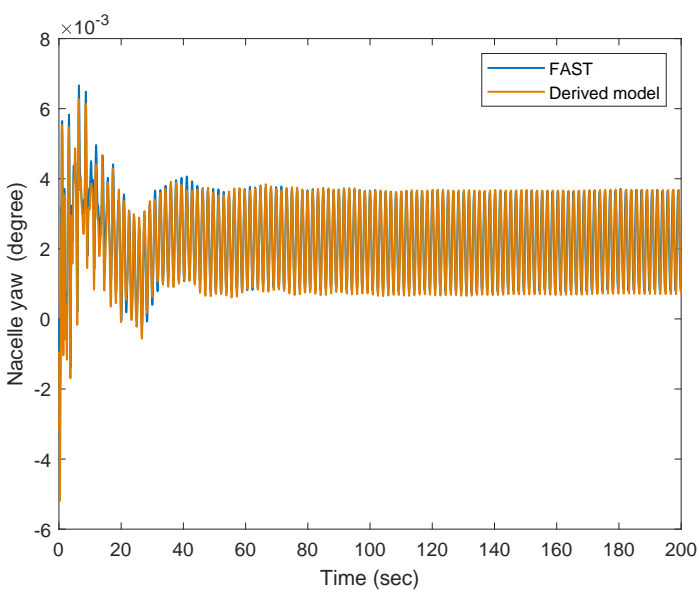

(e) Nacelle yaw rotation

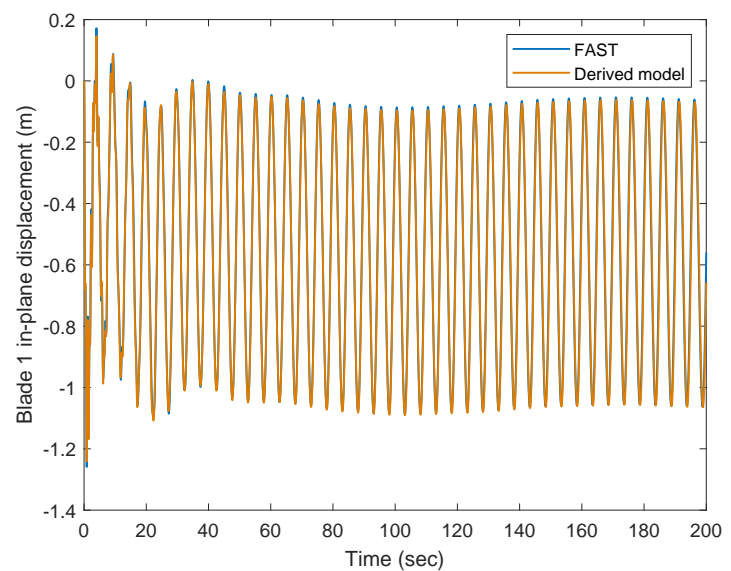

(b) Blade 1 in-plane displacement

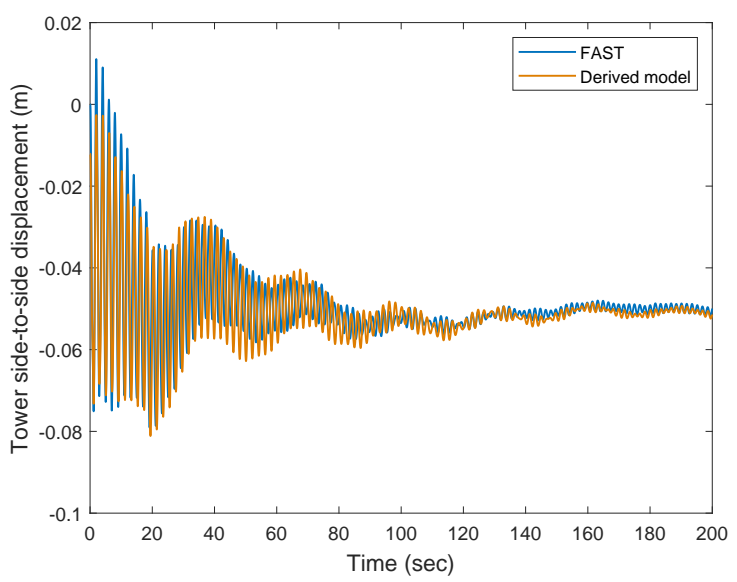

(d) Tower top side-to-side displacement

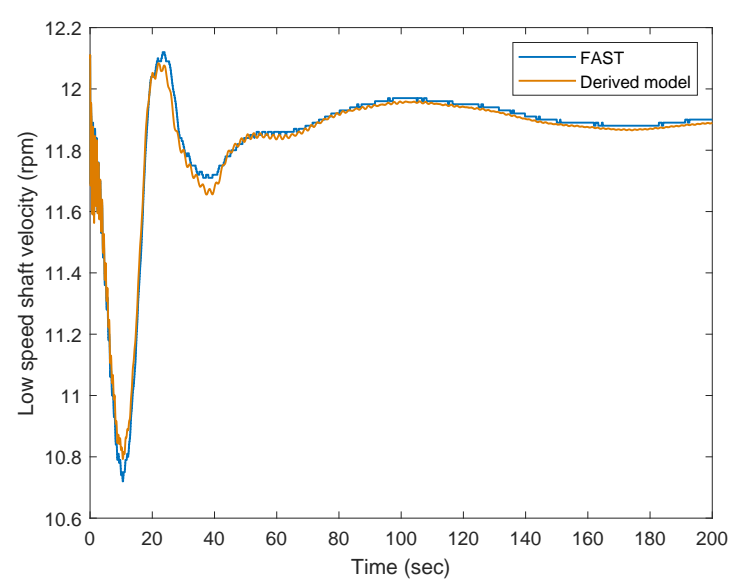

(f) Low speed shaft speed

Figure 4: Model verification: motion of the wind turbine tower, nacelle and blades 


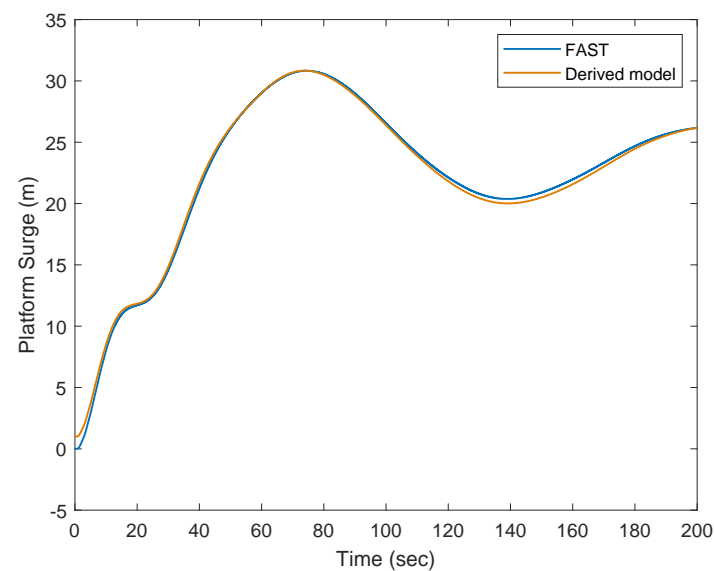

(a) Platform surge

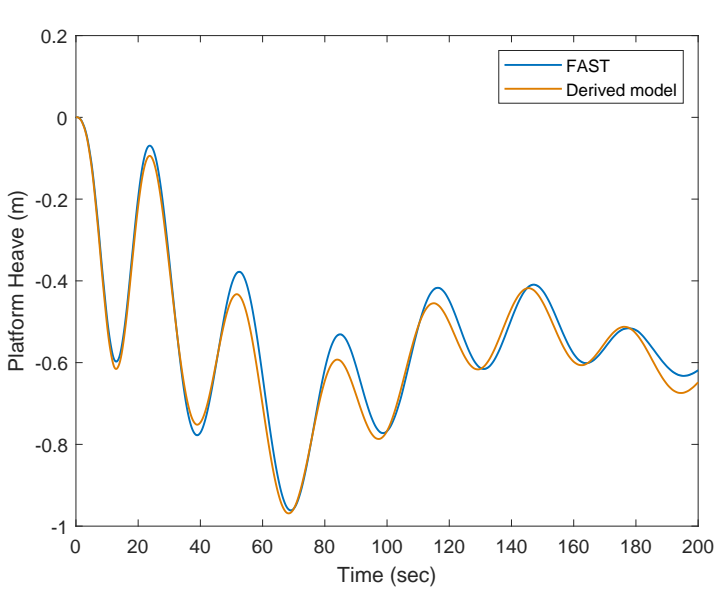

(c) Platform heave

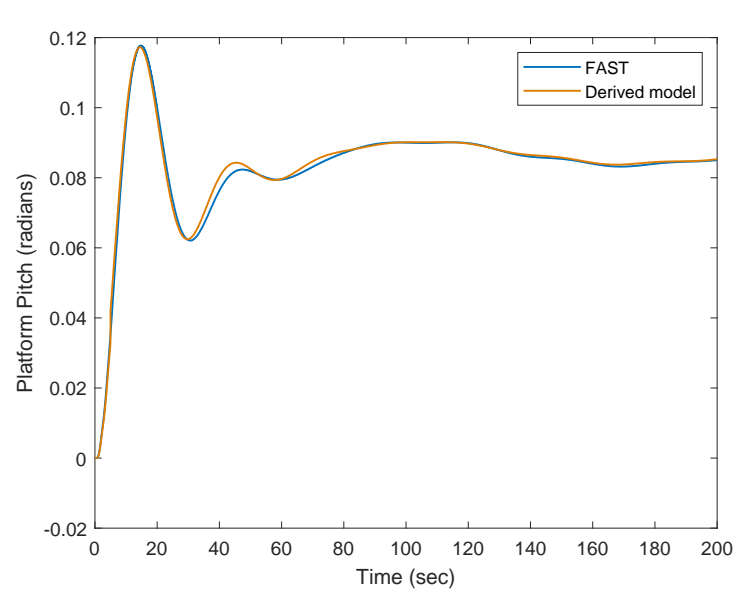

(e) Platform pitch

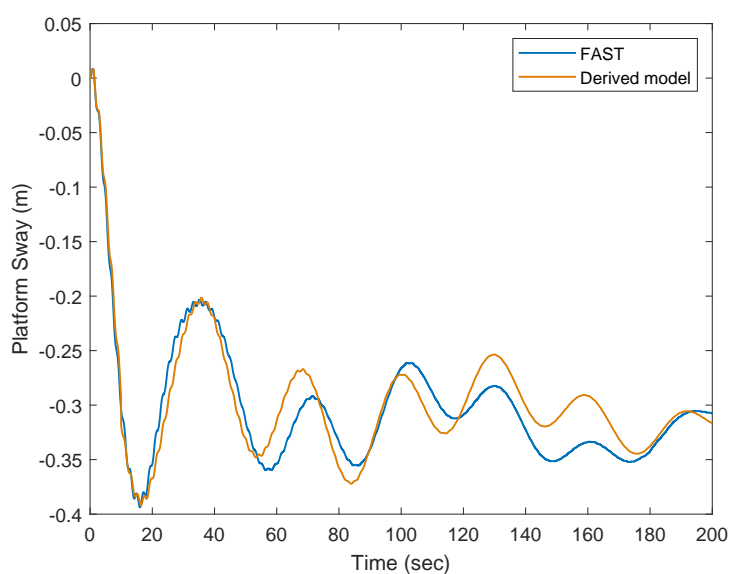

(b) Platform sway

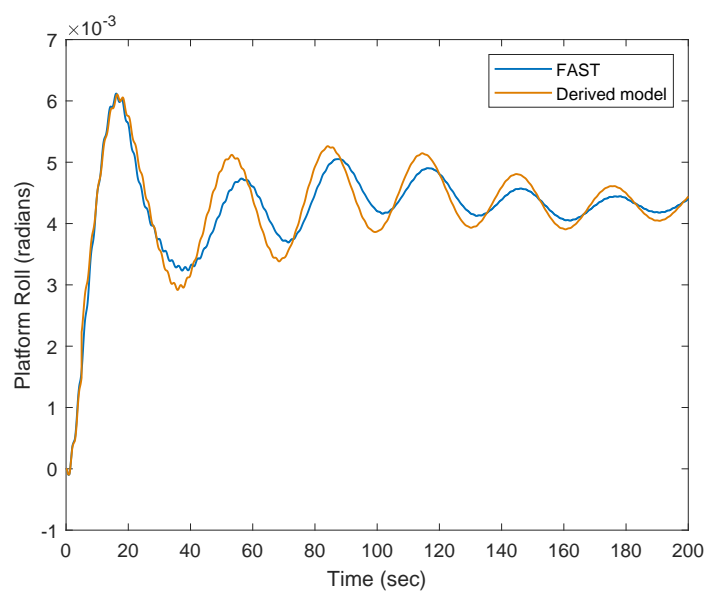

(d) Platform roll

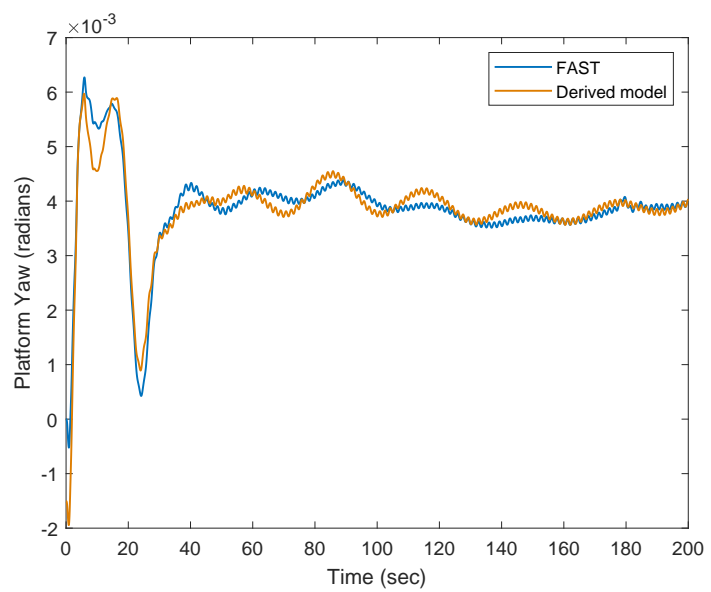

(f) Platform yaw

Figure 5: Model verification: motion of the wind turbine platform 
period is assumed to be $6 \mathrm{~s}$ for all simulations. The depth-dependent wave velocity and accelerations are obtained from equations 17,18,19 and 20 with underlying current. The offshore wind turbine is simulated without current and with an underlying current of uniform and linear profile. The surface current velocity is assumed to be $0.609 \mathrm{~m} / \mathrm{s}$ [87] in the along wind direction, which is the same as the wave propagation direction. The above sea-states represent a violent ocean. For illustration purposed, the controller performance is also evaluated under moderate sea-states of $H_{s}=2.25 \mathrm{~m}$ and $T_{p}=6.25 \mathrm{~s}$ and presented here.

The proposed pitch controller is employed in the FOWT and simulated under the above mentioned metocean conditions. Its performance is compared against the baseline pitch controller and the classical LQR controller. The three controllers used are defined as follows:

1. Baseline controller. The baseline controller is described in [91] which also provides the FORTRAN source code for the control algorithm. The same was rewritten in MATLAB[89] with changes prescribed in $[88]$.

2. $L Q R$ controller. The $\mathrm{LQR}$ pitch controller is designed using state weight matrix $\mathbf{Q}=5 \times \mathbf{I}$ and input weight matrix $\mathbf{R}=15000 \times \mathbf{I}$ for $14 \mathrm{~m} / \mathrm{s}$ wind speed and $\mathbf{Q}=300 \times \mathbf{I}$ and $\mathbf{R}=15000 \times \mathbf{I}$ for $25 \mathrm{~m} / \mathrm{s}$ wind speed. The weights are chosen a-priori after a few trial and errors to optimize the effort between the response states and pitch angles.

3. Wavelet- $L Q R$ controller $(W-L Q R)$. The advantage of the wavelet-LQR controller is that it is capable of applying different weights to different frequency bands. For that purpose, the signal from a finite internal $\left[\begin{array}{ll}t_{0} & t_{c}\end{array}\right]$ is filtered using ' $\mathrm{db} 6$ ' wavelet from the Daubechies wavelets [92]. The response is decomposed into 5 levels, where for a response sampled at $40 \mathrm{~Hz}$, the reconstructed approximate signal at $5^{\text {th }}$ level contains frequencies in the band $[0 \mathrm{~Hz} 1.2 \mathrm{~Hz}]$. This band contains the frequencies that are required to be suppressed, i.e., the rotational frequency of the wind turbine and the blade's natural frequency. Hence, the $5^{\text {th }}$ band becomes the lower bound where additional emphasis is placed on the response states by relaxing the control weight of this band to $\mathbf{R}_{L}=3000 \times \mathbf{I}$. All other parameters remain the same. Also, reconstructed detailed signals from levels 1 and 2 are disregarded in the estimation of control input.

\subsection{Reference wind speed $14 \mathrm{~m} / \mathrm{s}$ without underlying current}

The responses of the offshore wind turbine using the three different controllers and without any underlying current is shown in Figure 6. It can be observed from Figure 6(a) that excellent vibration reduction is obtained using the proposed wavelet controller for the blade out-of-plane motion. The LQR controller is capable of reducing the amplitude of the response but the peaks of the response are similar to that of the baseline controller. The corresponding Fourier spectrum of the response in Figure 6(b) shows that the $1 \mathrm{P}$ rotational frequency i.e., $0.2 \mathrm{~Hz}$ has been effectively suppressed by the proposed controller. It is also interesting to note that the two visible peaks below $0.2 \mathrm{~Hz}$ in the blade out-of-plane response spectrum is the effect of dynamic coupling between the blade-tower-platform. The response of the blade is heavily affected by the pitching motion of the platform and the fore-aft motion of the tower. However, the proposed controller is capable of suppressing these two peaks very effectively. Although the LQR controller is capable of mitigating these response frequencies, the wavelet-LQR controller performs better as is shown in the figures.

The tower fore-aft motion is shown in 6(c) with its Fourier spectrum in 6(d). Again, the wavelet-LQR controller performs significantly better than the baseline controller and LQR controller as can be observed from the time history. While the wavelet-LQR is capable of suppressing the various frequency peaks, the LQR controller is only capable of suppressing the lower frequency peak and higher peaks are observed in the higher frequency range. The response time history shows that, with the LQR controller, the response peaks are of greater amplitude than when the baseline controller is used.

Finally, the platform pitching motion is shown in 6(e) with its Fourier spectrum in 6(f). It can be observed that the pitching motion is dominated by a single frequency and it is mitigated effectively by the LQR controllers. But, again the wavelet-LQR controller performs better than the LQR controller as can be clearly observed from the two figures. 


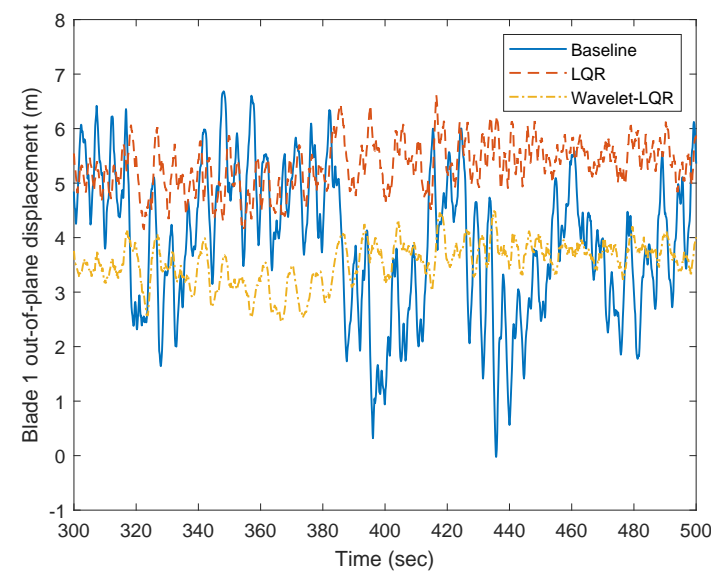

(a) Blade 1 out-of-plane displacement

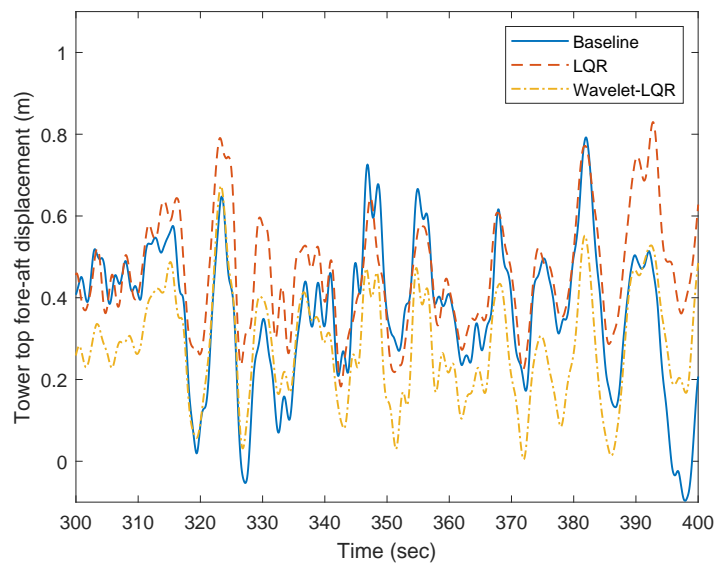

(c) Tower top fore-aft displacement

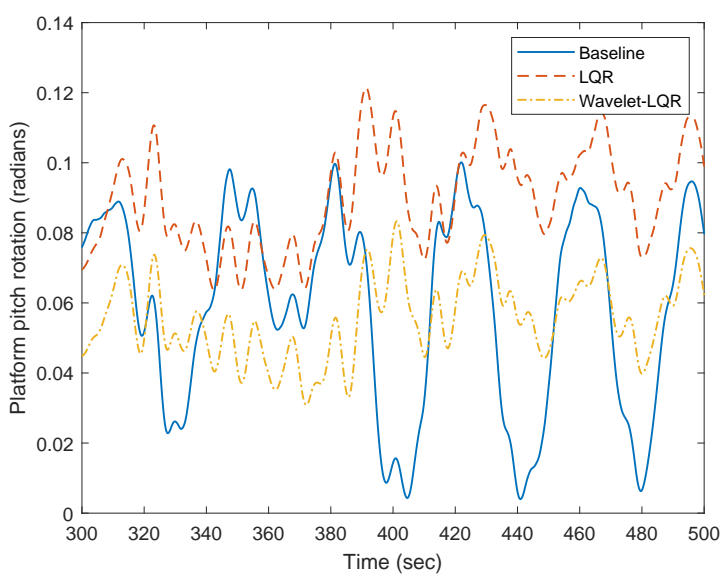

(e) Platform pitch rotation

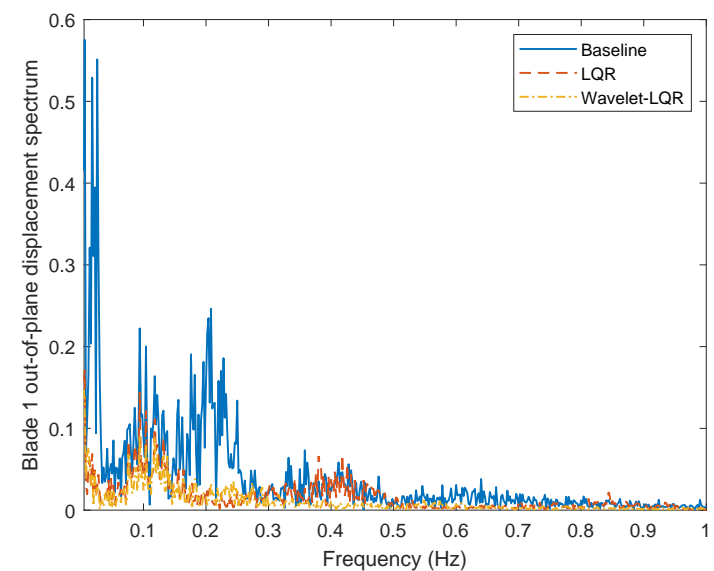

(b) Blade 1 out-of-plane displacement FFT

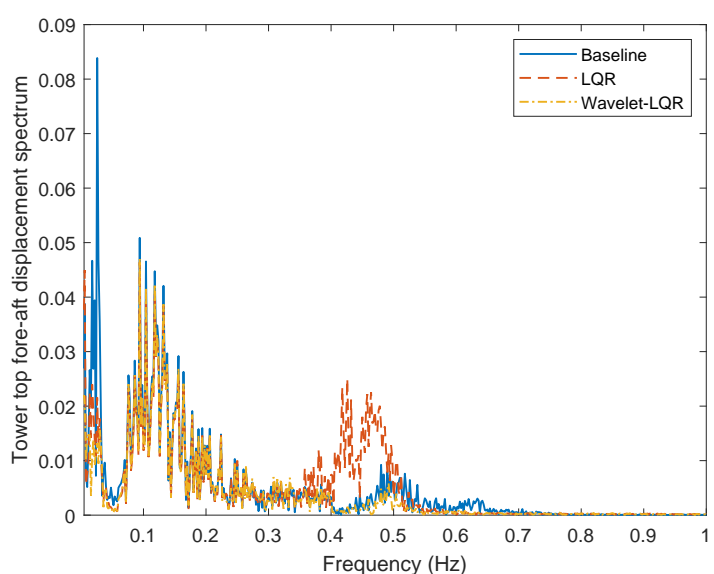

(d) Tower top fore-aft displacement FFT

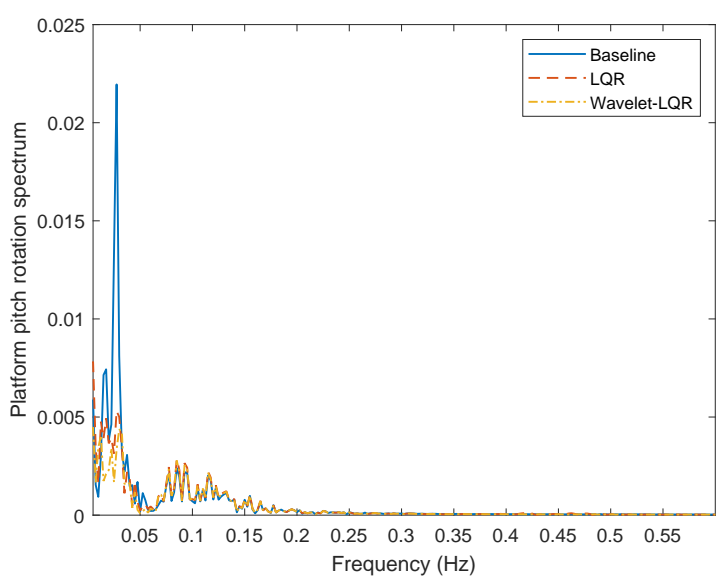

(f) Platform pitch rotation FFT

Figure 6: Wind turbine motion at reference wind speed $14 \mathrm{~m} / \mathrm{s}$ without underlying current 


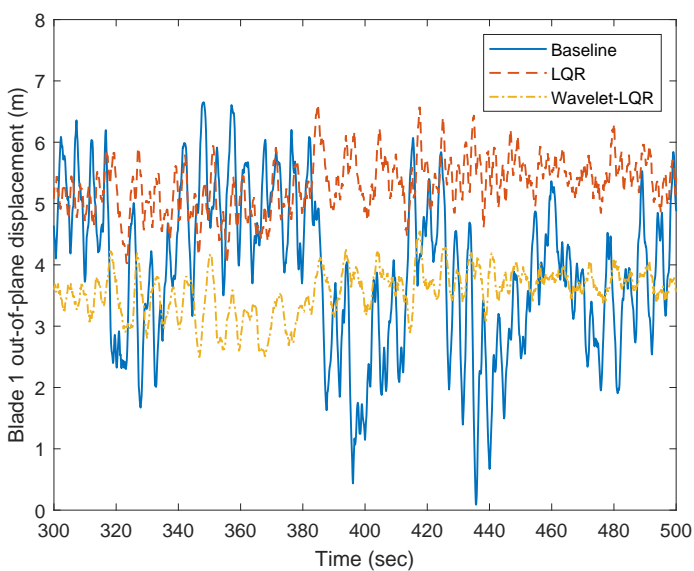

(a) Blade 1 out-of-plane displacement

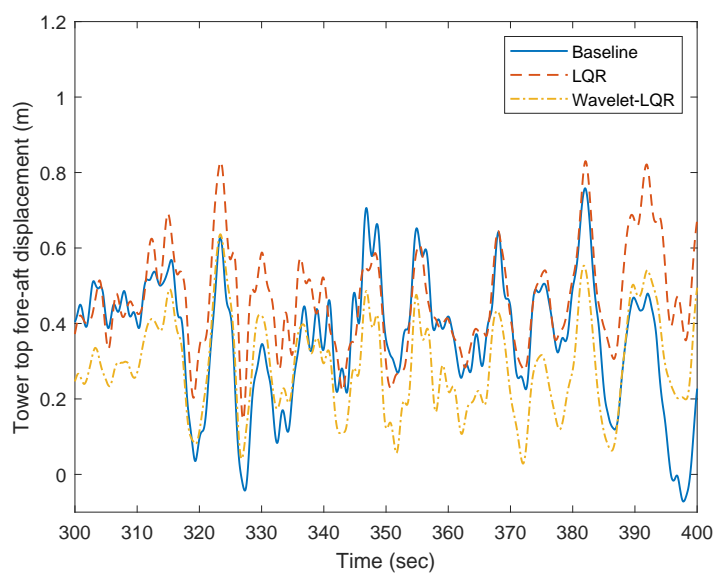

(c) Tower top fore-aft displacement

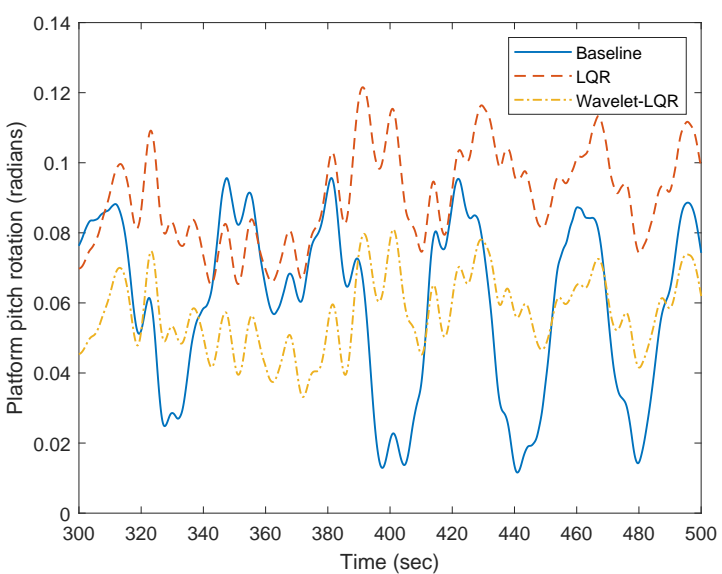

(e) Platform pitch rotation

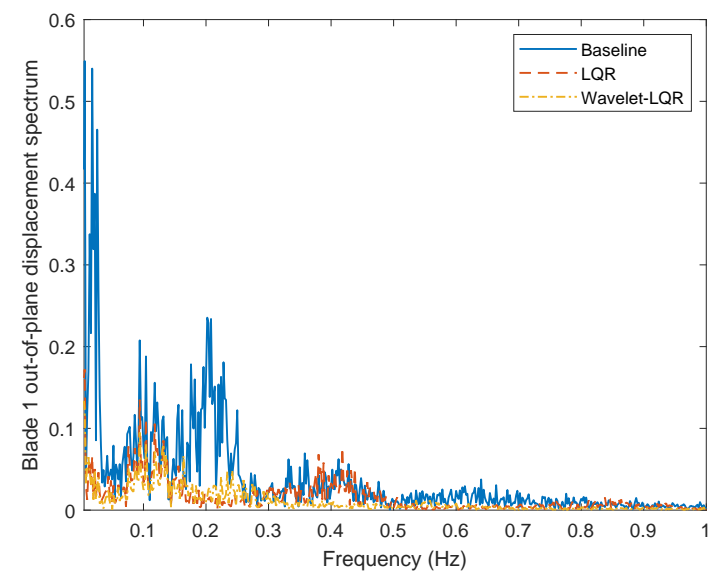

(b) Blade 1 out-of-plane displacement FFT

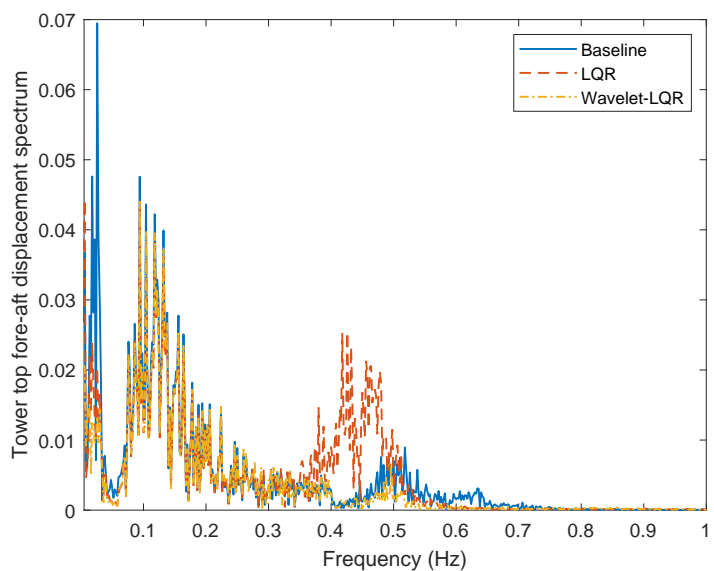

(d) Tower top fore-aft displacement FFT

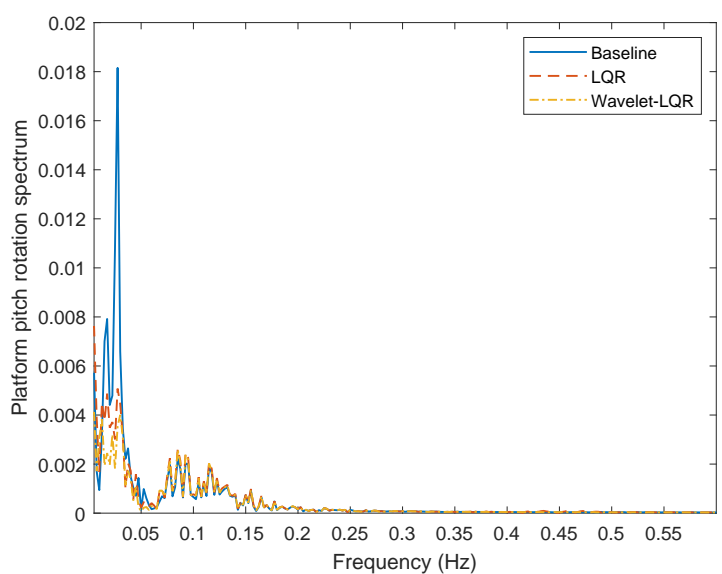

(f) Platform pitch rotation FFT

Figure 7: Wind turbine motion at reference wind speed $14 \mathrm{~m} / \mathrm{s}$ with underlying uniform current 


\subsection{Reference wind speed $14 \mathrm{~m} / \mathrm{s}$ with underlying current of uniform profile}

The offshore wind turbine is simulated next with an underlying current of a uniform profile at the same hub-height reference wind speed of $14 \mathrm{~m} / \mathrm{s}$ and the performance of the three different pitch controllers is compared in Figure 7. The response time histories, Fourier spectrum and controller performance are almost identical to that when the offshore wind turbine is simulated without the underlying current. The same conclusion can be made about the controller performance and is therefore not repeated. The only difference that can be observed is that the Fourier spectrum amplitudes are fractionally reduced. This is due to the fact that the underlying current decreases the wave turbulence as can be observed from the reduced peak of the wave spectrum in Figure 3 in the presence of an underlying current. Although this underlying current has negligible impact on the wind turbine degrees of freedom, the dynamic behaviour of the platform surge motion is heavily affected as shown in Figure 9. The current, when in the same direction as that of the wave, increases the platform surge motion. It can be also observed from Figure 9 that the underlying current reduces that turbulence in the surge motion of the platform. Since the dynamics of the surge motion much slower than the other components, it behaves as a static offset in the position of the wind turbine without any significant effect on the dynamics of the wind turbine and the performance of the controller.

\subsection{Reference wind speed $25 \mathrm{~m} / \mathrm{s}$ with underlying current of linear profile}

In this case, the performance of the three controllers is compared at a reference wind speed of $25 \mathrm{~m} / \mathrm{s}$ with an underlying current of a linear profile. The response time histories for the along-wind components along with their Fourier spectrum is shown in Figure 8. Again, a considerable reduction in blade out-of-plane using the proposed controller can be observed in Figure 8(a) and the peak associated with the $1 \mathrm{P}$ frequency of the wind turbine is clearly seen to be suppressed in Figure 8(b). It can be again observed that the proposed wavelet-LQR controller performs better than the baseline controller and the LQR pitch controller. Further 355 reduction in the tower fore-aft motion and the platform pitching motion using the wavelet-LQR controller is observed where the LQR pitch controller shows poor performance. The decrease in the response spectrum amplitudes of the tower fore-aft motion in Figure 8(d) and platform pitching motion in Figure 8(f) illustrates that the proposed controller is capable of mitigating the tower and the platform pitching motions through load reduction.

Tables 1 and 2 show the peak and the standard deviation of the blade, tower and platform motion associated with the baseline and the proposed Wavelet-LQR pitch controllers at the various met-ocean conditions considered in this paper. The percentage reduction over the baseline controller is also shown in the tables. The choice of the two wind speeds is based on the fact that, it lies at the bounds of region 3 of operational wind speeds. It has been shown that the response peaks and standard deviations are reduced with the proposed wavelet-LQR controller in both cases. A considerable reduction is obtained at $14 \mathrm{~m} / \mathrm{s}$ wind speed with the different current profiles. The results presented in Tables 1 and 2 show that at the cutout wind speed of $25 \mathrm{~m} / \mathrm{s}$ the performance of the proposed controller in mitigating the standard deviation of the responses drop slightly but promising reductions in response peaks are still observed. No significant difference in the controller performance is observed under different current profiles.

It has been shown the emphasis on $1 \mathrm{P}$ rotational frequency reduces the aerodynamic load associated with it and results in reduced pitching motion of the platform. However, this reduction of aerodynamic loads provides additional benefit in the form of reduced in-plane motion of the wind turbine which is not the objective of the controller. The blade in-plane motion, tower side-to-side motion, rotor speed and platform roll of the floating wind turbine for $14 \mathrm{~m} / \mathrm{s}$ and $25 \mathrm{~m} / \mathrm{s}$ are shown in Figure 10 and Figure 11 respectively. It can be observed that compared to the baseline controller the proposed wavelet-LQR controller is capable of reducing the structural vibrations by reducing the aerodynamic loads associated with 1P frequency. Further, the platform roll is also reduced thanks to the reduced load on the wind turbine. The reduction in platform pitch and roll establishes the fact that the proposed control not only ensures stability of the entire floating wind turbine but also reduces the rotation of the platform which is beneficial for power production.

It can also be observed from Figure 10(c) and Figure 11(c) that the variability in the rotor speed has increased. Although there is an increase in variability in the rotor speed it still tracks the rated speed of $12.1 \mathrm{rpm}$. While the baseline PI controller is designed solely to maintain the rotor speed at 12.1 


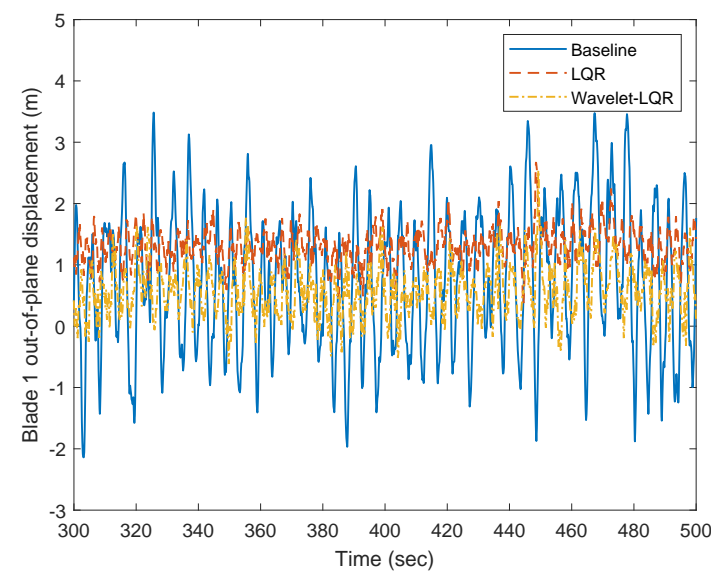

(a) Blade 1 out-of-plane displacement

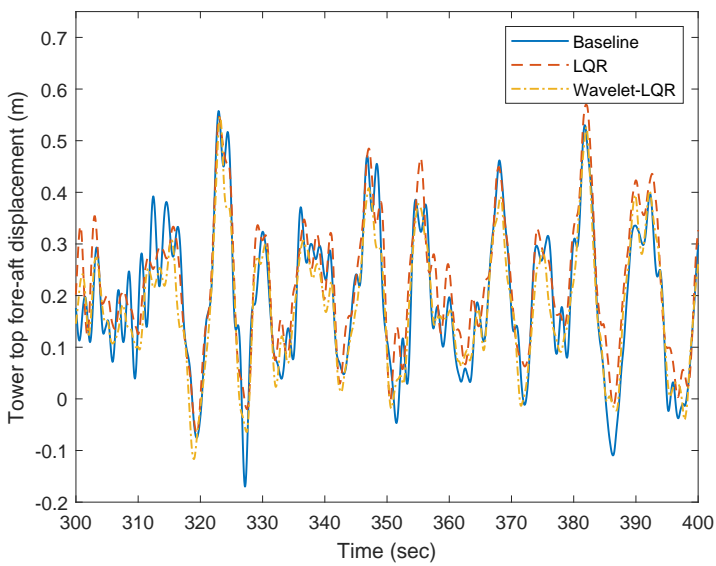

(c) Tower top fore-aft displacement

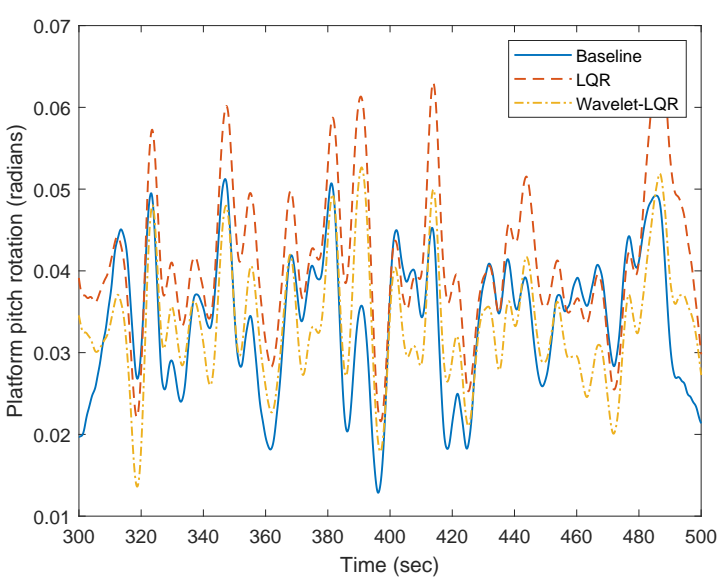

(e) Platform pitch rotation

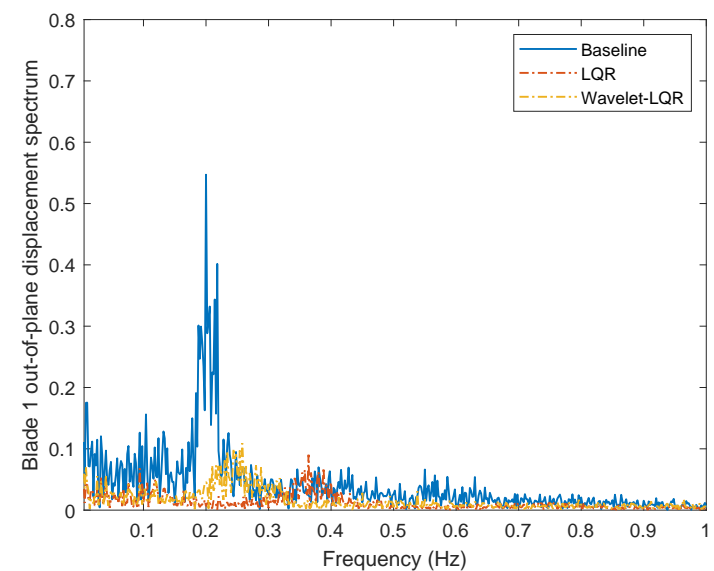

(b) Blade 1 out-of-plane displacement FFT

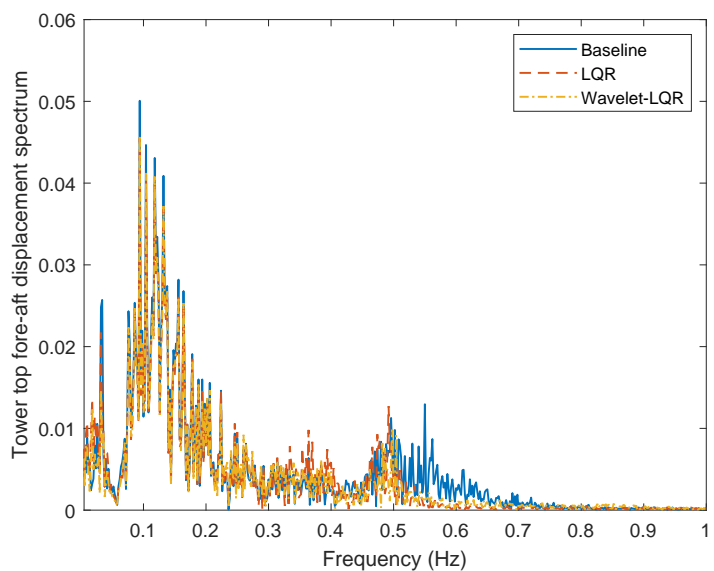

(d) Tower top fore-aft displacement FFT

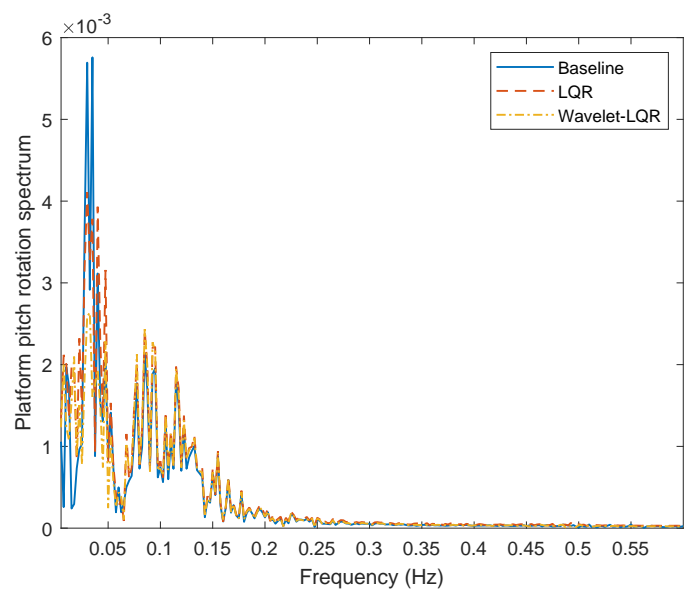

(f) Platform pitch rotation FFT

Figure 8: Wind turbine motion at reference wind speed $25 \mathrm{~m} / \mathrm{s}$ with underlying linear current 


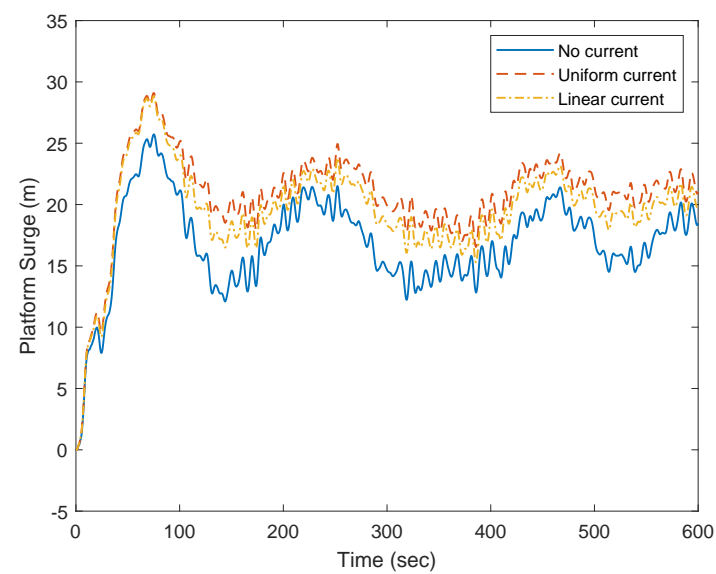

(a) Reference wind speed $14 \mathrm{~m} / \mathrm{s}$

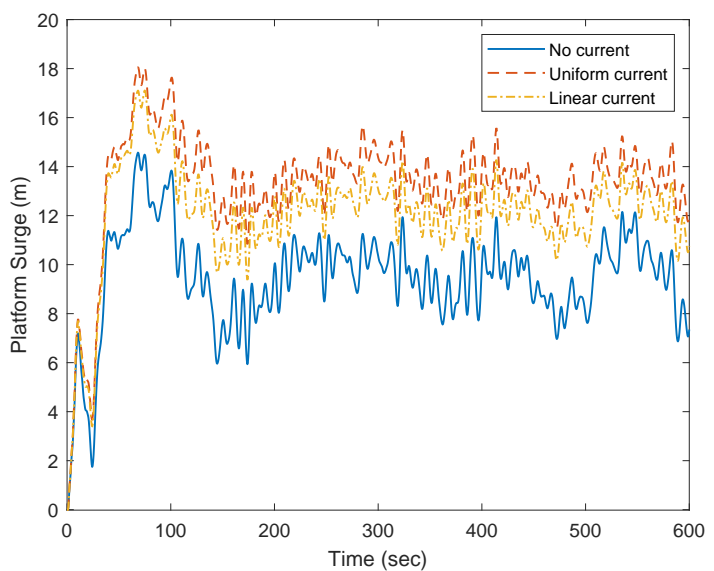

(b) Reference wind speed $25 \mathrm{~m} / \mathrm{s}$

Figure 9: Static offset created by the underlying current

Table 1: Peak response magnitudes using the three different controllers

\begin{tabular}{|c|c|c|c|c|c|c|c|c|c|c|}
\hline \multirow{2}{*}{ Current } & \multirow{2}{*}{$\begin{array}{l}\text { Wind } \\
\text { speed }\end{array}$} & \multicolumn{3}{|c|}{ Blade OOP displacement $(\mathrm{m})$} & \multicolumn{3}{|c|}{ Tower FA displacement (m) } & \multicolumn{3}{|c|}{ Platform pitch rotation (rad) } \\
\hline & & Baseline & W-LQR & P.R $(\%)$ & Baseline & W-LQR & P.R(\%) & Baseline & W-LQR & P.R $(\%)$ \\
\hline \multirow{2}{*}{$\begin{array}{l}\mathrm{W} / \mathrm{O} \\
\text { Current }\end{array}$} & $14 \mathrm{~ms}^{-1}$ & 6.864 & 4.491 & 35 & 0.807 & 0.755 & 6 & 0.100 & 0.083 & 17 \\
\hline & $25 \mathrm{~ms}^{-1}$ & 3.902 & 1.939 & 50 & 0.677 & 0.630 & 7 & 0.061 & 0.052 & 15 \\
\hline \multirow{2}{*}{$\begin{array}{l}\text { Uniform } \\
\text { Current }\end{array}$} & $14 \mathrm{~ms}^{-1}$ & 6.788 & 4.554 & 33 & 0.778 & 0.705 & 9 & 0.096 & 0.081 & 15 \\
\hline & $25 \mathrm{~ms}^{-1}$ & 3.871 & 2.530 & 35 & 0.634 & 0.601 & 5 & 0.058 & 0.053 & 8 \\
\hline \multirow[t]{2}{*}{$\begin{array}{l}\text { Linear } \\
\text { Current }\end{array}$} & $14 \mathrm{~ms}^{-1}$ & 6.786 & 4.456 & 34 & 0.782 & 0.703 & 10 & 0.097 & 0.082 & 16 \\
\hline & $25 \mathrm{~ms}^{-1}$ & 3.873 & 2.541 & 34 & 0.638 & 0.586 & 8 & 0.058 & 0.053 & 10 \\
\hline
\end{tabular}

rpm, the Wavelet-LQR controller is designed to reduce structural vibrations. The LQR gains are selected appropriately to keep the rotor speed around the rated value while aiming for greater load reduction. In this study, it has been found the standard deviation of the low-speed-shaft/rotor speed from $12.1 \mathrm{rpm}$ using the baseline PI controller is $1.21 \mathrm{rpm}$ and $1.40 \mathrm{rmp}$ for wind speeds of $14 \mathrm{~m} / \mathrm{s}$ and $25 \mathrm{~m} / \mathrm{s}$ respectively. For the proposed Wavelet-LQR controller the standard deviations of the rotor speed for the respective wind speeds are $1.72 \mathrm{rpm}$ and $1.87 \mathrm{rmp}$. While there is an increase in the standard deviation, the coefficient of variation in the worst scenario is still under $15 \%$. Also, as pointed out by [62, 93], individual wind turbine power variability will be less important as an offshore wind turbine will almost certainly be situated in a large wind farm and the total output of the farm will be predominantly dictated by the spatial and temporal variations of the farm rather than the variability of a single turbine. Hence, this increase in individual wind turbine power variability is judged to be acceptable considering the promising reduction in structural loads. This trade-off between structural response mitigation and rotor speed maintenance can prove to be beneficial in extending the design life of the wind turbine components. It must be noted here that the 
Table 2: Response standard deviations using the three different controllers

\begin{tabular}{|c|c|c|c|c|c|c|c|c|c|c|c|c|}
\hline \multirow{2}{*}{ Current } & \multirow{2}{*}{$\begin{array}{l}\text { Wind } \\
\text { speed } \\
(\mathrm{m} / \mathrm{s})\end{array}$} & \multicolumn{3}{|c|}{ Blade OOP disp. (m) } & \multicolumn{3}{|c|}{ Tower FA disp. (m) } & \multicolumn{3}{|c|}{ Platform pit. rot. (rad) } & \multicolumn{2}{|c|}{ Rotor speed (rpm) } \\
\hline & & $\begin{array}{c}\text { Base- } \\
\text { line }\end{array}$ & $\begin{array}{c}\text { W- } \\
\text { LQR }\end{array}$ & $\begin{array}{l}P . R \\
(\%)\end{array}$ & $\begin{array}{c}\text { Base- } \\
\text { line }\end{array}$ & $\begin{array}{c}\text { W- } \\
\text { LQR }\end{array}$ & $\begin{array}{l}P . R \\
(\%)\end{array}$ & $\begin{array}{c}\text { Base- } \\
\text { line }\end{array}$ & $\begin{array}{c}\text { W- } \\
\text { LQR }\end{array}$ & $\begin{array}{l}P . R \\
(\%)\end{array}$ & $\begin{array}{c}\text { Base- } \\
\text { line }\end{array}$ & $\begin{array}{c}\text { W- } \\
\text { LQR }\end{array}$ \\
\hline \multirow{2}{*}{$\begin{array}{l}\mathrm{W} / \mathrm{O} \\
\text { Current }\end{array}$} & 14 & 1.212 & 0.320 & 74 & 0.161 & 0.124 & 23 & 0.023 & 0.011 & 54 & 1.21 & 1.72 \\
\hline & 25 & 1.099 & 0.404 & 63 & 0.140 & 0.126 & 10 & 0.011 & 0.008 & 25 & 1.40 & 1.87 \\
\hline \multirow{2}{*}{$\begin{array}{l}\text { Uniform } \\
\text { Current }\end{array}$} & 14 & 1.176 & 0.316 & 73 & 0.150 & 0.117 & 22 & 0.020 & 0.010 & 52 & 1.19 & 1.70 \\
\hline & 25 & 1.092 & 0.392 & 64 & 0.130 & 0.119 & 8 & 0.009 & 0.008 & 15 & 1.39 & 1.83 \\
\hline \multirow{2}{*}{$\begin{array}{l}\text { Linear } \\
\text { Current }\end{array}$} & 14 & 1.183 & 0.316 & 73 & 0.151 & 0.117 & 23 & 0.021 & 0.010 & 52 & 1.20 & 1.71 \\
\hline & 25 & 1.091 & 0.388 & 64 & 0.130 & 0.118 & 9 & 0.009 & 0.007 & 18 & 1.40 & 1.86 \\
\hline
\end{tabular}

controller is designed with the primary aim of vibration control and rotor speed regulation is not included. In principle, increasing the weight on the states, or conversely decreasing the weight on the control input, will improve vibration control. However, this is at a cost of increased pitch actuation and rotor speed variability. In this paper, the weights are selected so that excellent vibration control is achieved at a cost of slightly increased rotor speed error. The authors would to point out here that it is possible to reduce rotor speed error by sacrificing on vibration control. The controller weight matrices are design parameters that can be determined based on the requirement. Another important aspect of the controller design is the pitching rate of the blades which demonstrates the rate of use of pitch actuators. It has been observed that the maximum pitch rate for the baseline PI pitch controller is $1.63 \mathrm{deg} / \mathrm{s}$ and $0.42 \mathrm{deg} / \mathrm{s}$ for wind speeds of $14 \mathrm{~m} / \mathrm{s}$ and $25 \mathrm{~m} / \mathrm{s}$ respectively. However, with the Wavelet-LQR pitch controller the maximum pitch rate is saturated at $8 \mathrm{deg} / \mathrm{s}$ which is the design specification. Hence, the improved structural response if obtained from an increased use of pitch actuation.

Lastly, as it was mentioned before the proposed controller is compared against the baseline controller at a hub height wind speed of $14 \mathrm{~m} / \mathrm{s}$, moderate sea-states and an underlying current of linear profile and is shown in Figure 12 and Figure 13. A similar observation can be made about the controller performance where a significant reduction in structural responses is achieved at a cost of increased rotor speed variability. The pitch and roll of the platform are reduced while the rotor speed still tracks the rated value. As mentioned earlier this increase in variability is judged to be acceptable given the significant amount of reduction in structural responses that is achieved.

\section{Conclusion}

This paper proposes the use of a wavelet-LQR based individual pitch controller for response mitigation and load reduction in spar-type floating offshore wind turbines considering wave-current interactions. A reduced order model using the blade out-of-plane and tower fore-aft degrees of freedom is used to develop the controller. The proposed wavelet-LQR controller has the capability of assigning frequency band dependent LQR gains. This capability has been used in this study to emphasize on the $1 \mathrm{P}$ frequency of the wind turbine along with the blade out-of-plane natural frequency. The controller is compared against the baseline controller and the classical LQR controller. The numerical results presented in this paper show that the wavelet-LQR controller perform better than the baseline controller and the LQR controller for different met-ocean conditions in reducing structural loads. The wind speeds are selected so that they lie on the bound of region 3 of operational wind speeds. The performance at the two different wind speeds shows that although excellent response mitigation is obtained at lower wind speed as compared to higher wind speed, 


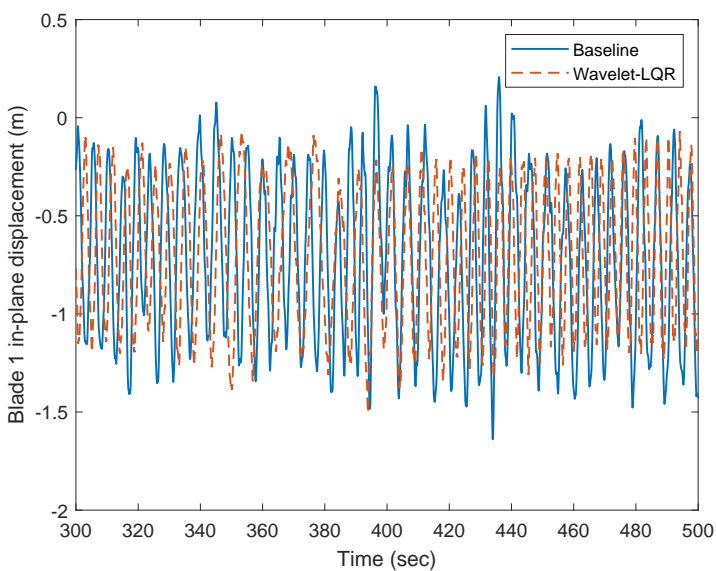

(a) Blade in-plane displacement

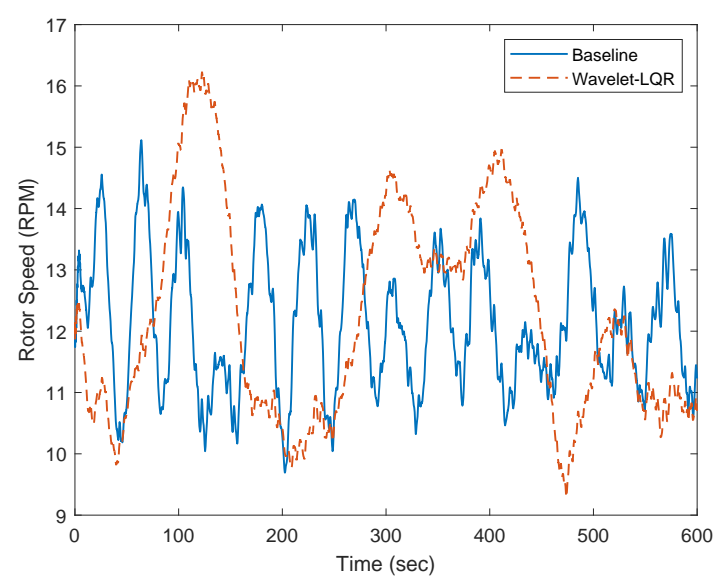

(c) Low speed shaft/rotor speed

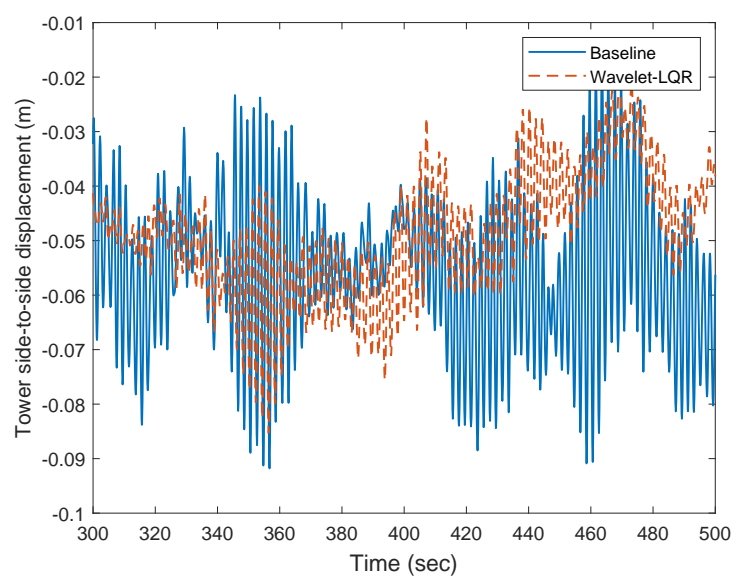

(b) Tower side-to-side displacement

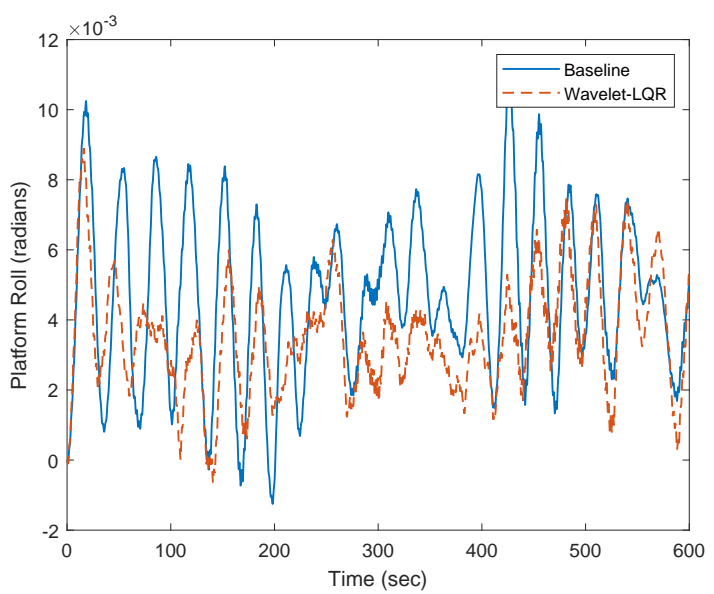

(d) Platform roll

Figure 10: Hub height reference wind speed $14 \mathrm{~m} / \mathrm{s}$ and underlying current of linear profile

better performance than the baseline controller is obtained in full range of wind speeds. The emphasis on the $1 \mathrm{P}$ frequency of the wind turbine reduces the aerodynamic loads which in turn reduces vibration in tower fore-aft and platform pitching motion of the wind turbine. It has been shown that the pitching of the platform contributes significantly to the dynamics of the blade and the tower. However, the proposed controller is capable of minimizing the pitching motion of the platform together with the blade out-of-plane motion and tower fore-aft motion. Additional benefit is achieved in the form of reduction of blade in-plane motion, tower side-to-side motion and platform roll that arises from aerodynamic load reduction associated with the $1 \mathrm{P}$ frequency of the wind turbine. The proposed controller not only ensures the stability of the entire wind turbine but also reduces the platform pitch and roll. It has been observed that this improved structural response is obtained at a cost of increased use of pitch actuation. It has also been shown that the improved structural response of the offshore wind turbine results in an increase in deviation from the rate rotor speed which leads to increased power variability. However, as has been mention in the previous section the significance of this individual wind turbine power variability will be further minimized when an entire wind farm is considered. This trade-off between vibration reduction and rotor speed improvement can prove to be beneficial in increasing the design life of the wind turbine components.

The investigation on wave-current interaction showed that the underlying current has no significant 


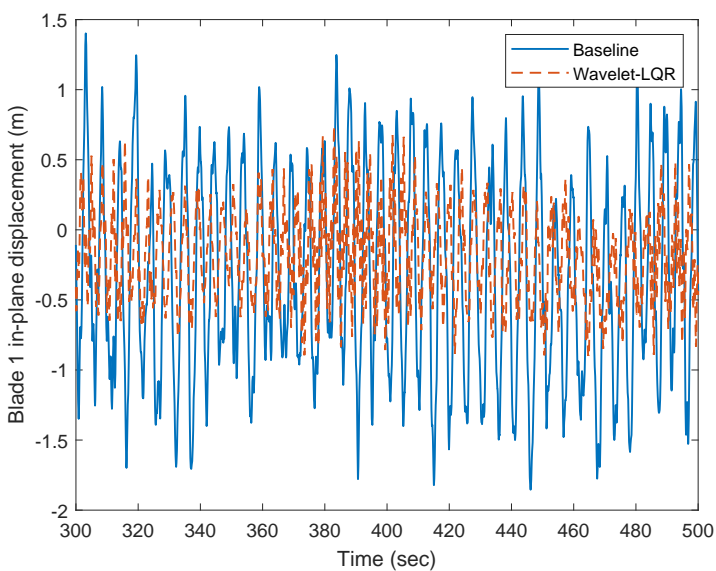

(a) Blade in-plane displacement

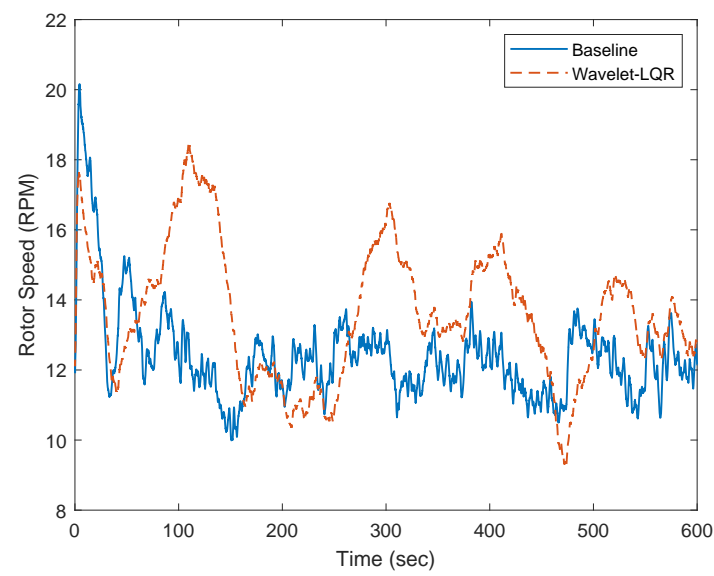

(c) Low speed shaft/rotor speed

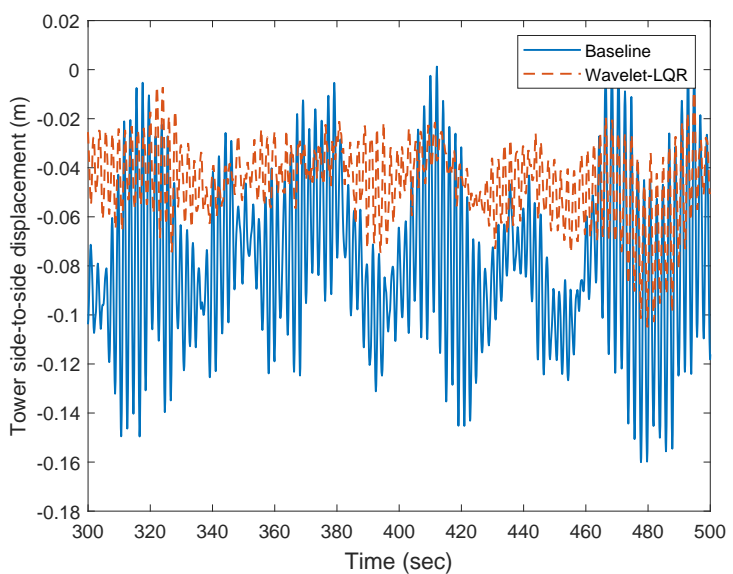

(b) Tower side-to-side displacement

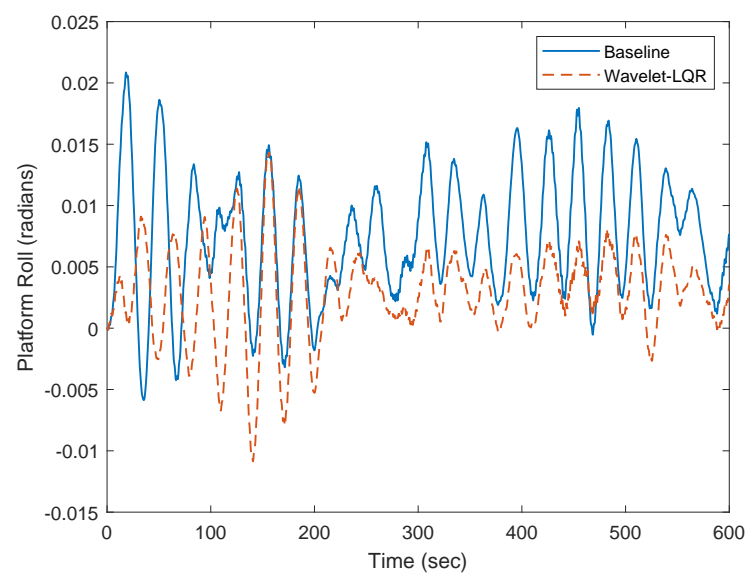

(d) Platform roll

Figure 11: Hub height reference wind speed $25 \mathrm{~m} / \mathrm{s}$ and underlying current of linear profile

effect on the performance of the controller. The results presented also show the importance of wave-current interaction on offshore wind turbines. The effect of vorticity in presence of ocean currents can generate complex fluid motion [94, 95]. The dynamics of the spar can be significantly affected by the presence of vorticity [96-98] which requires further investigation and will be addressed in future works.

\section{Acknowledgement}

The second author, L. Chen, is supported by the Irish Research Council through the Government of Ireland Postdoctoral Fellowship (Project ID: GOIPD/2017/1260), which is gratefully acknowledged.

\section{Appendix A.}

Degrees of freedom: 


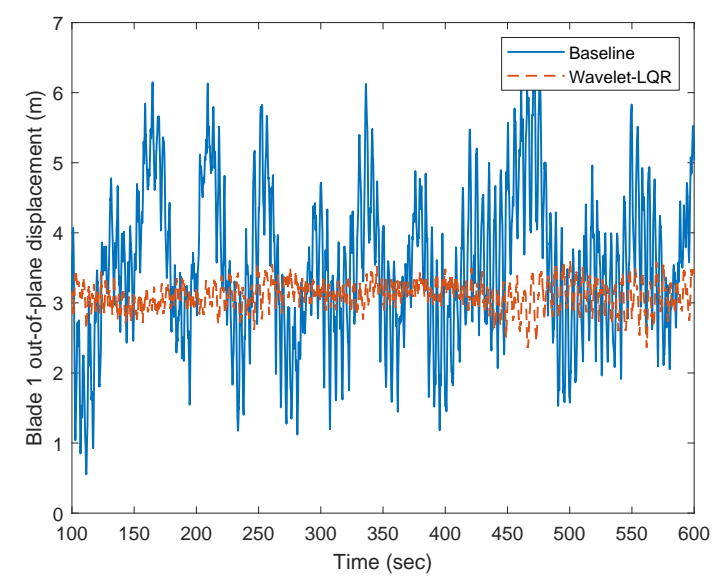

(a) Blade out-of-plane displacement

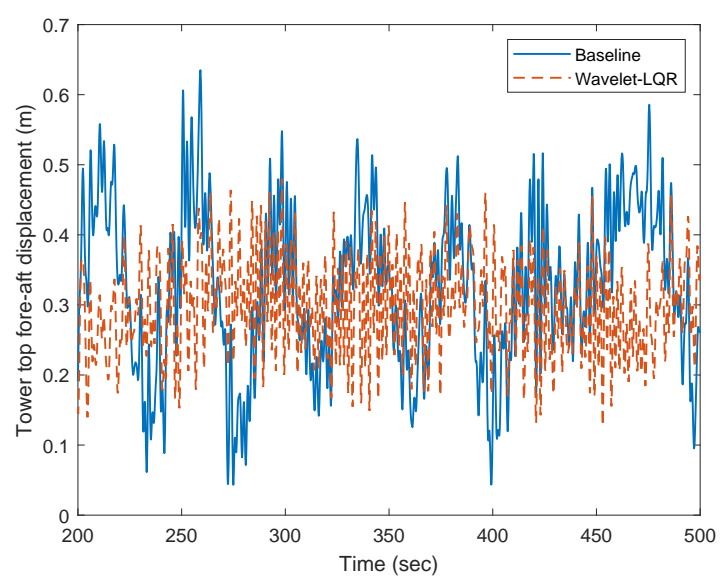

(c) Tower top fore-aft displacement

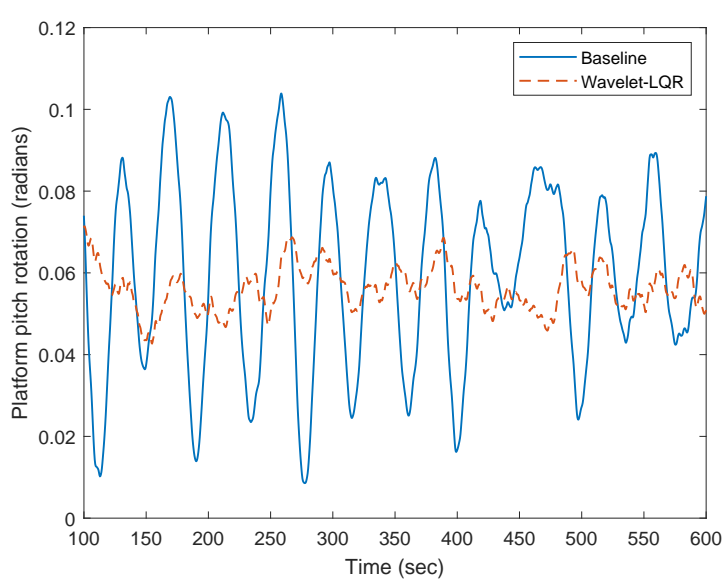

(e) Platform pitch

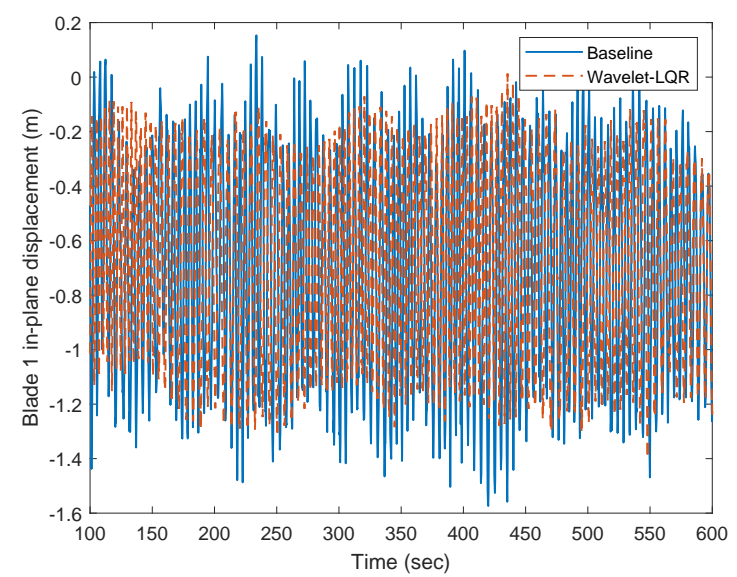

(b) Blade in-plane displacement

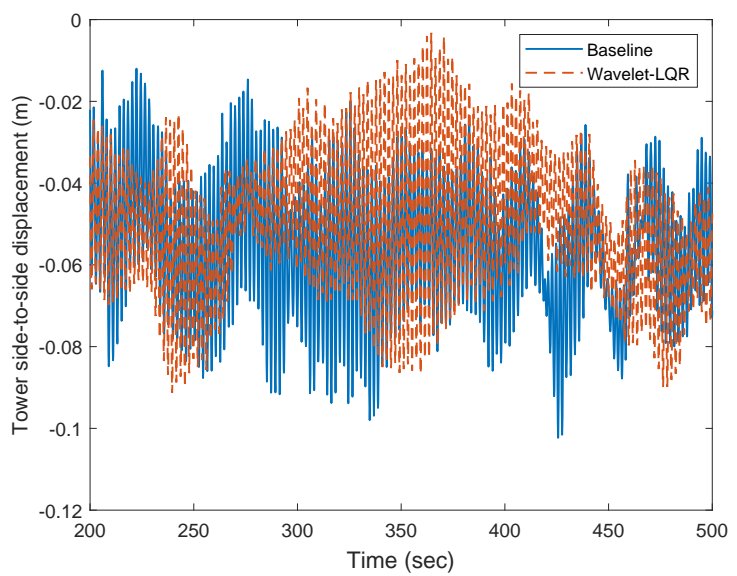

(d) Tower top side-to-side displacement

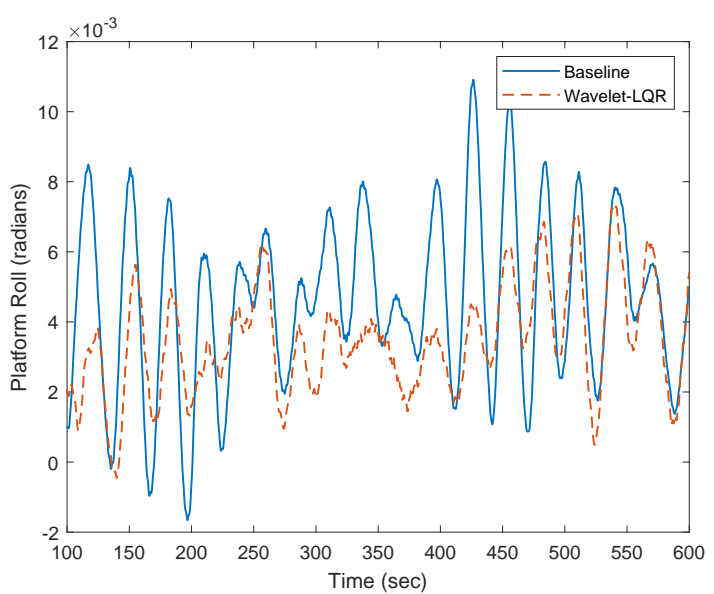

(f) Platform Roll

Figure 12: Hub height reference wind speed $14 \mathrm{~m} / \mathrm{s}$ and underlying current of linear profile and moderate sea states 


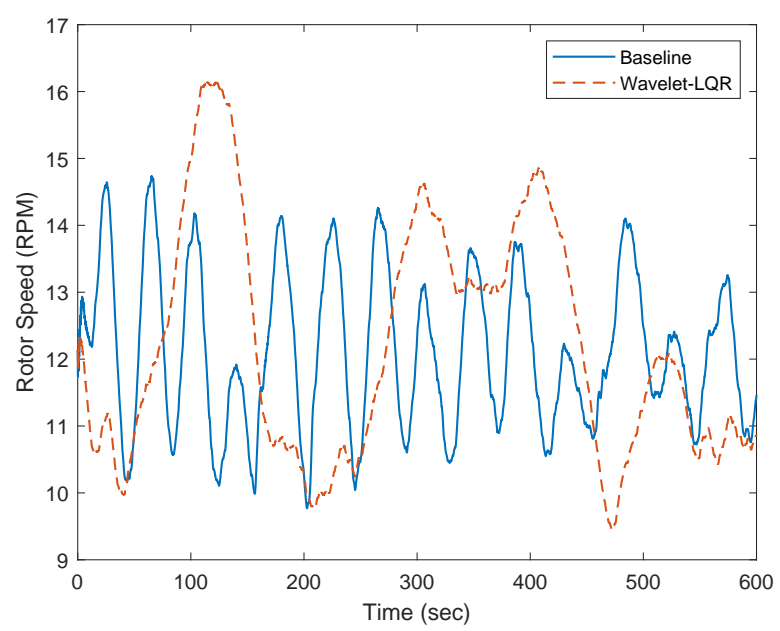

Figure 13: Rotor speed at wind speed $14 \mathrm{~m} / \mathrm{s}$ and underlying current of linear profile and moderate sea states

$\begin{array}{ll}q_{S g} & \text { Platform surge } \\ q_{S w} & \text { Platform sway } \\ q_{H v} & \text { Platform heave } \\ q_{R} & \text { Platform roll } \\ q_{P} & \text { Platform pitch } \\ q_{Y} & \text { Platform yaw } \\ q_{T F A 1} & \text { First tower fore-aft bending mode } \\ q_{T F A 2} & \text { Second tower fore-aft bending mode } \\ q_{T S S 1} & \text { First tower side-to-side bending mode } \\ q_{T S S 2} & \text { Second tower side-to-side bending mode } \\ q_{y a w} & \text { Nacelle yaw } \\ q_{\text {GeAz }} & \text { Generator azimuth angle } \\ q_{D r T r} & \text { Drive-train torsional flexibility } \\ q_{B i F 1} & \text { First flapwise bending mode for } i^{t h} \text { blade } \\ q_{B i F 2} & \text { Second flapwise bending mode for } i^{t h} \text { blade } \\ q_{B i E 1} & \text { First edgewise bending mode for } i^{t h} \text { blade }\end{array}$

\section{References}

[1] Lackner, M.A.. Controlling platform motions and reducing blade loads for floating wind turbines. Wind Engineering 2009;33(6):541-553.

[2] Lackner, M.A., Rotea, M.A.. Passive structural control of offshore wind turbines. Wind energy 2011;14(3):373-388.

[3] Staino, A., Basu, B., Nielsen, S.R.. Actuator control of edgewise vibrations in wind turbine blades. Journal of Sound and Vibration 2012;331(6):1233-1256.

[4] Fitzgerald, B., Basu, B., Nielsen, S.R.. Active tuned mass dampers for control of in-plane vibrations of wind turbine blades. Structural Control and Health Monitoring 2013;20(12):1377-1396.

[5] Dinh, V.N., Basu, B.. Passive control of floating offshore wind turbine nacelle and spar vibrations by multiple tuned mass dampers. Structural Control and Health Monitoring 2015;22(1):152-176.

[6] Hemmati, A., Oterkus, E., Barltrop, N.. Fragility reduction of offshore wind turbines using tuned liquid column dampers. Soil Dynamics and Earthquake Engineering 2019;125:105705.

[7] Basu, B., Zhang, Z., Nielsen, S.R.. Damping of edgewise vibration in wind turbine blades by means of circular liquid dampers. Wind Energy 2016;19(2):213-226. 
[8] Dinh, V.N., Basu, B., Nagarajaiah, S.. Semi-active control of vibrations of spar type floating offshore wind turbines. Smart Struct Syst 2016;18(4):683-705.

[9] Sonmez, E., Nagarajaiah, S., Sun, C., Basu, B.. A study on semi-active tuned liquid column dampers (stlcds) for structural response reduction under random excitations. Journal of Sound and Vibration 2016;362:1-15.

10] Fitzgerald, B., Sarkar, S., Staino, A.. Improved reliability of wind turbine towers with active tuned mass dampers (atmds). Journal of Sound and Vibration 2018;419:103-122.

[11] Fitzgerald, B., Basu, B.. Cable connected active tuned mass dampers for control of in-plane vibrations of wind turbine blades. Journal of Sound and Vibration 2014;333(23):5980-6004.

[12] Sarkar, S., Chakraborty, A.. Optimal design of semiactive mr-tlcd for along-wind vibration control of horizontal axis wind turbine tower. Structural Control and Health Monitoring 2018;25(2).

[13] Hemmati, A., Oterkus, E.. Semi-active structural control of offshore wind turbines considering damage development. Journal of Marine Science and Engineering 2018;6(3):102.

[14] Hemmati, A., Oterkus, E., Khorasanchi, M.. Vibration suppression of offshore wind turbine foundations using tuned liquid column dampers and tuned mass dampers. Ocean Engineering 2019;172:286-295.

[15] Stol, K.A., Zhao, W., Wright, A.D.. Individual blade pitch control for the controls advanced research turbine (cart). Journal of solar energy engineering 2006;128(4):498-505.

[16] Zhao, W., Stol, K.. Individual blade pitch for active yaw control of a horizontal-axis wind turbine. In: 45th AIAA Aerospace Sciences Meeting and Exhibit. 2007, p. 1022.

[17] Nam, Y., Kien, P.T., La, Y.H.. Alleviating the tower mechanical load of multi-mw wind turbines with lqr control. Journal of Power Electronics 2013;13(6):1024-1031.

[18] Kristalny, M., Madjidian, D., Knudsen, T.. On using wind speed preview to reduce wind turbine tower oscillations. IEEE Transactions on Control Systems Technology 2013;21(4):1191-1198.

[19] Fleming, P., Wingerden, J.W., Wright, A.. Comparing state-space multivariable controls to multi-siso controls for load reduction of drivetrain-coupled modes on wind turbines through field-testing. In: 50th AIAA Aerospace Sciences Meeting including the New Horizons Forum and Aerospace Exposition. 2012, p. 1152.

[20] De Battista, H., Mantz, R.J., Christiansen, C.F.. Dynamical sliding mode power control of wind driven induction generators. IEEE transactions on energy conversion 2000;15(4):451-457.

[21] Bossanyi, E.. Individual blade pitch control for load reduction. Wind energy 2003;6(2):119-128.

[22] Jelavić, M., Petrović, V., Perić, N.. Estimation based individual pitch control of wind turbine. Automatika 2010;51(2):181-192.

[23] Bossanyi, E.A., Fleming, P.A., Wright, A.D.. Validation of individual pitch control by field tests on two-and three-bladed wind turbines. IEEE Transactions on Control Systems Technology 2013;21(4):1067-1078.

[24] Bossanyi, E.. Further load reductions with individual pitch control. Wind energy 2005;8(4):481-485.

[25] Bottasso, C., Croce, A., Riboldi, C., Nam, Y.. Multi-layer control architecture for the reduction of deterministic and non-deterministic loads on wind turbines. Renewable energy 2013;51:159-169.

[26] Petrović, V., Jelavić, M., Baotić, M.. Advanced control algorithms for reduction of wind turbine structural loads. Renewable Energy 2015;76:418-431.

[27] Petrović, V., Baotić, M., Perić, N.. Reduction of wind turbine tower oscillations based on individual pitch control. In: Control \& Automation (MED), 2012 20th Mediterranean Conference on. IEEE; 2012, p. 1499-1505.

[28] Dou, Z., Peng, S., Ling, Z., Cai, X.. Reduction of wind turbine torque fluctuation using individual pitch control based on edgewise moment. Research Journal of Applied Sciences, Engineering and Technology 2013;5(24):5665-5676.

[29] Selvam, K., Kanev, S., van Wingerden, J.W., van Engelen, T., Verhaegen, M.. Feedback-feedforward individual pitch control for wind turbine load reduction. International Journal of Robust and Nonlinear Control: IFAC-Affiliated Journal 2009;19(1):72-91.

510 [30] Schuler, S., Schlipf, D., Cheng, P.W., Allgöwer, F.. $\ell_{1}$-optimal control of large wind turbines. IEEE Transactions on Control Systems Technology 2013;21(4):1079-1089.

[31] Larsen, T.J., Madsen, H.A., Thomsen, K.. Active load reduction using individual pitch, based on local blade flow measurements. Wind Energy: An International Journal for Progress and Applications in Wind Power Conversion Technology $2005 ; 8(1): 67-80$.

515 [32] Thomsen, S.C., Niemann, H., Poulsen, N.K.. Individual pitch control of wind turbines using local inflow measurements. IFAC Proceedings Volumes 2008;41(2):5587-5592.

[33] Stol, K., Balas, M.. Periodic disturbance accommodating control for speed regulation of wind turbines. In: ASME 2002 Wind Energy Symposium. American Society of Mechanical Engineers; 2002, p. 310-320.

[34] Stol, K.A., Balas, M.J.. Periodic disturbance accommodating control for blade load mitigation in wind turbines. Journal of solar energy engineering 2003;125(4):379-385.

[35] Stol, K., Balas, M.. Full-state feedback control of a variable-speed wind turbine: a comparison of periodic and constant gains. Journal of solar energy engineering 2001;123(4):319-326.

[36] Girsang, I.P., Dhupia, J.S.. Collective pitch control of wind turbines using stochastic disturbance accommodating control. Wind Engineering 2013;37(5):517-533.

[37] Cheon, J., Kwon, S., Choi, Y.. Design of a pitch controller using disturbance accommodating control for wind turbines under stochastic environments. In: Industrial Electronics (ISIE), 2014 IEEE 23rd International Symposium on. IEEE; 2014, p. 2572-2577.

[38] Hassan, H., ElShafei, A., Farag, W., Saad, M.. A robust lmi-based pitch controller for large wind turbines. Renewable energy 2012;44:63-71.

[39] Fakharzadeh, A., Jamshidi, F., Talebnezhad, L.. New approach for optimizing energy by adjusting the trade-off 
coefficient in wind turbines. Energy, Sustainability and Society 2013;3(1):19.

[40] Pan, T., Ma, Z.. Wind turbine individual pitch control for load reduction based on fuzzy controller design. Proceedings of the Institution of Mechanical Engineers, Part I: Journal of Systems and Control Engineering 2013;227(3):320-328.

[41] Lasheen, A., Elshafei, A.L.. Wind-turbine collective-pitch control via a fuzzy predictive algorithm. Renewable Energy 2016;87:298-306.

[42] Asgharnia, A., Shahnazi, R., Jamali, A.. Performance and robustness of optimal fractional fuzzy pid controllers for pitch control of a wind turbine using chaotic optimization algorithms. ISA transactions 2018;

[43] Han, B., Zhou, L., Yang, F., Xiang, Z.. Individual pitch controller based on fuzzy logic control for wind turbine load mitigation. IET Renewable Power Generation 2016;10(5):687-693.

44] Boukhezzar, B., Lupu, L., Siguerdidjane, H., Hand, M.. Multivariable control strategy for variable speed, variable pitch wind turbines. Renewable Energy 2007;32(8):1273-1287.

[45] Mirzaei, M., Soltani, M., Poulsen, N.K., Niemann, H.H.. Model predictive control of wind turbines using uncertain lidar measurements. In: American Control Conference (ACC), 2013. IEEE; 2013, p. 2235-2240.

[46] Mirzaei, M., Soltani, M., Poulsen, N.K., Niemann, H.H.. An mpc approach to individual pitch control of wind turbines using uncertain lidar measurements. In: Control Conference (ECC), 2013 European. IEEE; 2013, p. 490-495.

[47] Scholbrock, A., Fleming, P., Fingersh, L., Wright, A., Schlipf, D., Haizmann, F., et al. Field testing lidar-based feed-forward controls on the nrel controls advanced research turbine. In: 51st AIAA Aerospace Sciences Meeting Including the New Horizons Forum and Aerospace Exposition. 2013, p. 818.

[48] Xia, A., Hu, G., Li, Z., Huang, D., Wang, F.. Self-optimizing pitch control for large scale wind turbine based on adrc. In: IOP Conference Series: Materials Science and Engineering; vol. 301. IOP Publishing; 2018, p. 012155.

[49] Gao, R., Gao, Z.. Pitch control for wind turbine systems using optimization, estimation and compensation. Renewable Energy 2016;91:501-515.

[50] Ren, Y., Li, L., Brindley, J., Jiang, L.. Nonlinear pi control for variable pitch wind turbine. Control Engineering Practice 2016;50:84-94.

[51] Lin, Z., Liu, J., Wu, Q., Niu, Y.. Mixed h $2 / \mathrm{h}$ pitch control of wind turbine with a markovian jump model. International Journal of Control 2018;91(1):156-169.

[52] Yuan, Y., Tang, J.. Adaptive pitch control of wind turbine for load mitigation under structural uncertainties. Renewable Energy 2017;105:483-494.

[53] Lio, W.H., Jones, B.L., Lu, Q., Rossiter, J.A.. Fundamental performance similarities between individual pitch control strategies for wind turbines. International Journal of Control 2017;90(1):37-52.

[54] Lan, J., Patton, R.J., Zhu, X.. Fault-tolerant wind turbine pitch control using adaptive sliding mode estimation. Renewable Energy 2018;116:219-231.

[55] Dahbi, A., Nait-Said, N., Nait-Said, M.S.. A novel combined mppt-pitch angle control for wide range variable speed wind turbine based on neural network. International Journal of Hydrogen Energy 2016;41(22):9427-9442.

56] Namik, H., Stol, K.. Individual blade pitch control of floating offshore wind turbines. Wind Energy: An International Journal for Progress and Applications in Wind Power Conversion Technology 2010;13(1):74-85.

[57] Namik, H., Stol, K.. Performance analysis of individual blade pitch control of offshore wind turbines on two floating platforms. Mechatronics 2011;21(4):691-703.

[58] Namik, H., Stol, K.. Individual blade pitch control of a spar-buoy floating wind turbine. system 2014;1(3):6.

59] Li, Q., Kamada, Y., Maeda, T., Murata, J., Iida, K., Okumura, Y.. Fundamental study on aerodynamic force of floating offshore wind turbine with cyclic pitch mechanism. Energy 2016;99:20-31.

[60] Basu, B., Nagarajaiah, S.. A wavelet-based time-varying adaptive lqr algorithm for structural control. Engineering structures 2008;30(9):2470-2477.

[61] Basu, B., Nagarajaiah, S.. Multiscale wavelet-lqr controller for linear time varying systems. Journal of Engineering Mechanics 2010;136(9):1143-1151.

[62] Fitzgerald, B., Staino, A., Basu, B.. Wavelet-based individual blade pitch control for vibration control of wind turbine blades. Structural Control and Health Monitoring 2019;26(1):e2284.

[63] Chen, L., Basu, B.. Wave-current interaction effects on structural responses of floating offshore wind turbines. Wind Energy 2019;22(2):327-339.

64] Chen, L., Basu, B.. Fatigue load estimation of a spar-type floating offshore wind turbine considering wave-current interactions. Int J Fatigue 2018;116:421-428. doi:10.1016/j.ijfatigue.2018.06.002.

[65] Jonkman, J.M., Buhl Jr, M.L.. Fast user's guide-updated august 2005. Tech. Rep.; National Renewable Energy Laboratory (NREL), Golden, CO.; 2005.

[66] Kane, T.R., Levinson, D.A.. Dynamics, theory and applications. McGraw Hill; 1985.

J] Jonkman, J.M.. Dynamics modeling and loads analysis of an offshore floating wind turbine. University of Colorado at Boulder; 2007.

[68] Jonkman, B.J.. Turbsim user's guide: Version 1.50. Tech. Rep.; National Renewable Energy Lab.(NREL), Golden, CO (United States); 2009.

69] Burton, T., Jenkins, N., Sharpe, D., Bossanyi, E.. Wind energy handbook. John Wiley \& Sons; 2011. 2005.

[71] Hansen, M.O.. Aerodynamics of wind turbines. Routledge; 2015.

[72] Ning, S.A.. A simple solution method for the blade element momentum equations with guaranteed convergence. Wind Energy 2014;17(9):1327-1345.

[73] Ning, A., Hayman, G., Damiani, R., Jonkman, J.M.. Development and validation of a new blade element momentum 
skewed-wake model within aerodyn. In: 33rd Wind Energy Symposium. 2015, p. 0215.

[74] Dinh, V.N., Basu, B.. Impact of spar-nacelle-blade coupling on the edgewise response of floating offshore wind turbines. Coupled Systems Mechanics 2013;2(3):231-253.

[75] Chen, L., Basu, B., Nielsen, S.R.K.. A coupled finite difference mooring dynamics model for floating offshore wind turbine analysis. Ocean Eng 2018;162:304-315. doi:10.1016/j.oceaneng. 2018.05.001.

76] Tjavaras, A.A.. The dynamics of highly extensible cables. Thesis; Massachusetts Institute of Technology; 1996.

[77] Tjavaras, A.A., Zhu, Q., Liu, Y., Triantafyllou, M.S., Yue, D.K.P.. The mechanics of highly-extensible cables. J Sound Vib 1998;213(4):709-737. doi:10.1006/jsvi.1998.1526.

78] Gobat, J.I., Grosenbaugh, M.A.. Time-domain numerical simulation of ocean cable structures. Ocean Eng 2006;33(10):1373-1400. doi:10.1016/j.oceaneng. 2005.07.012.

79] Huang, N.E., Chen, D.T., Tung, C.C., Smith, J.R.. Interactions between steady won-uniform currents and gravity waves with applications for current measurements. Journal of Physical Oceanography 1972;2(4):420-431. doi:10.1175/ $1520-0485(1972) 002<0420$ : IBSWUC $>2.0 . \mathrm{CO} ; 2$.

[80] Tung, C.C., Huang, N.E.. Influence of current on statistical properties of waves. Journal of Waterways, Harbors \& Coast Eng Div 1974;100(4):267-278

[81] Thomas, G.P.. Wave-current interactions: an experimental and numerical study. part 1. linear waves. J Fluid Mech 1981;110:457-474. doi:10.1017/S0022112081000839.

[82] Silva, M.C., Vitola, M.A., Esperança, P.T.T., Sphaier, S.H., Levi, C.A.. Numerical simulations of wave-current flow in an ocean basin. Appl Ocean Resear 2016;61:32-41. doi:10.1016/j.apor.2016.10.005.

83] Ismail, N.M.. Wave-current models for design of marine structures. J Waterw Port Coast Ocean Eng 1984;110(4):432-447. doi:10.1061/(ASCE) 0733-950X (1984) 110:4(432).

[84] Hedges, T.S.. Some effects of currents on wave spectra. In: Proceedings of the first Indian Conference in Ocean Engineering; vol. 1. 1981, p. 30-35.

[85] Hedges, T.S., Anastasiou, K., Gabriel, D.. Interaction of random waves and currents. J Waterw Port Coast Ocean Eng 1985;111(2):275-288 doi:10.1061/(ASCE) 0733-950X (1984) 110:4(432).

[86] Phillips, O.M.. The Dynamics of Upper Ocean. Cambridge University Press; 1977.

87] Azcona, J., Palacio, D., Munduate, X., González, L., Nygaard, T.A.. Impact of mooring lines dynamics on the fatigue and ultimate loads of three offshore floating wind turbines computed with iec 61400-3 guideline. Wind Energy 2017;20(5):797-813.

88] Jonkman, J.M.. Definition of the Floating System for Phase IV of OC3. Citeseer; 2010.

[89] MATLAB, . version 9.4.0 (R2018a). Natick, Massachusetts: The MathWorks Inc.; 2018

[90] Pierson Jr, W.J., Moskowitz, L.. A proposed spectral form for fully developed wind seas based on the similarity theory of sa kitaigorodskii. Journal of geophysical research 1964;69(24):5181-5190.

[91] Jonkman, J.M., Butterfield, S., Musial, W., Scott, G.. Definition of a 5-MW reference wind turbine for offshore system development. National Renewable Energy Laboratory Golden, CO; 2009.

[92] Daubechies, I.. Ten lectures on wavelets; vol. 61. Siam; 1992.

[93] Lackner, M.A.. An investigation of variable power collective pitch control for load mitigation of floating offshore wind turbines. Wind Energy 2013;16(4):519-528.

[94] Basu, B.. Irrotational two-dimensional free-surface steady water flows over a flat bed with underlying currents. Nonlinear Analysis: Theory, Methods \& Applications 2016;147:110-124.

[95] Basu, B.. On some properties of velocity field for two dimensional rotational steady water waves. Nonlinear Analysis $2019 ; 184: 17-34$

[96] Gabbai, R., Benaroya, H.. An overview of modeling and experiments of vortex-induced vibration of circular cylinders. Journal of Sound and Vibration 2005;282(3-5):575-616.

97] Irani, M., Finn, L.. Model testing for vortex induced motions of spar platforms. In: ASME 2004 23rd International Conference on Offshore Mechanics and Arctic Engineering. American Society of Mechanical Engineers; 2004 , p. 605-610.

[98] Carlson, D.W., Modarres-Sadeghi, Y.. Vortex-induced vibration of spar platforms for floating offshore wind turbines. Wind Energy 2018;21(11):1169-1176. 